\title{
Professional Development in a Rural Cluster of Schools
}

by

\section{Llyween Janet Delves Couper}

\begin{abstract}
A thesis
submitted to the Victoria University of Wellington in fulfilment of the requirements for the degree of Master of Arts in Education
\end{abstract}

Victoria University of Wellington 2004 


\begin{abstract}
This study investigated a model of professional development that has been developed by the principals of a cluster of six New Zealand rural schools. It explored the reasons why the principals chose this model of self initiated professional development, how professional development was achieved and the factors that sustained it. Data were gathered using a variety of tools, including interviews with the principals and an external professional development provider, observations, a survey and a limited historical documentation search.
\end{abstract}

Results indicated that the need for regular social and professional interaction with other principals who work in similar communities was highly valued by all participants. They believed that they were unique and capable of providing professional leadership and collegial support for their cluster. The change from meeting for organizing sporting events to providing relevant professional development was strongly influenced by a mentoring contract offered by the Ministry of Education.

Implications for the provision of professional development specifically for rural schools and their learning communities are discussed and suggest that the principals of rural schools have specific needs. Their professional development should include opportunities for social and professional interaction with cooperative decisions and activities initiated by them. 


\section{Acknowledgements}

I am grateful to many people who have helped and supported me throughout this study. I would like to acknowledge and give my thanks to:

Victoria University of Wellington-especially Elizabeth Jones who was my supervisor throughout this study for all the advice, guidance and encouragement. Thank you also to the learning support staff for their support.

Christchurch College of Education for the research grant that enabled the data collection for the study. Thank you especially to Carol Saysell and Dave Clements at the Henry Field library at Christchurch College of Education for searches for material for the literature review and their continuing interest in the research.

The principals who participated enthusiastically in the study, and despite their heavy workloads, gave their time freely.

My colleagues, at Christchurch College of Education and, Resource Teachers Learning and Behaviour who have been encouraging and shown an interest in the study.

Mary Hancox for her generosity in sharing information and guidance, particularly during the writing of the thesis. The study has been a much richer experience because it has been shared with another professional friend and colleague.

Family, friends and neighbours, who have listened, questioned and contributed their thoughts and opinions about rural schools and professional development, over the last two years. 


\section{Table of Contents}

Abstract

$\begin{array}{ll}\text { Acknowledgements } & \text { iii }\end{array}$

Table of Contents

List of Tables

List of Appendices $\quad$ vii

Introduction $\quad 1$

CHAPTER ONE

Professional Development 6

Models of Professional Development 8

Collaborative Learning Communities 15

Summary $\quad 22$

CHAPTER TWO

Rural Schools and Professional Development 24

Summary $\quad 29$

The Research Questions $\quad 30$

CHAPTER THREE

Methodology

Defining the Cluster Model 31

The Participants 32

The Setting $\quad 32$

The Research Design 34

Six Key Aspects for Investigation $\quad 00$

Links Between Aspects for Investigation

and Three Research Questions 00

Procedures and Data Collection 37

Data Sources and Analysis $\quad 39$

Key Principal Interview

The Questionnaire

Participant Principals' Interviews

Historical Files Examination

Observations of Meetings

External provider Interview

Reliability and Validity $\quad 00$

Summary $\quad 44$

CHAPTER FOUR

Results 
Introduction

45

Profiles of the Principals 46

Results Reported Under Six Aspects: 48

1.Description

48

2.Administration

3.Interpersonal Relationships

4.Content of Professional Development

5.The Meetings

Observations of Meeting

00

6.Professional Development Supports

Key Findings

Summary

\section{CHAPTER FIVE}

\section{Discussion}

Research Questions

Why are the principals of six rural schools

using a cluster model for most of their professional development?

How is professional development achieved?

What factors sustain the cluster model?

Limitations

Conclusions and Implications of the Study

88

Tables 


\section{List of Appendices}

Appendix A Ethical approval Christchurch College of Education. 102

Appendix B Approval for study, Victoria University of Wellington. 104

Appendix C Ethical Approval Victoria, University of Wellington. 105

$\begin{array}{lll}\text { Appendix D Participant Consent Forms } & 106\end{array}$

$\begin{array}{lll}\text { Appendix E Survey } & 109\end{array}$

$\begin{array}{lll}\text { Appendix F Participant Interviews } & 118\end{array}$

$\begin{array}{lll}\text { Appendix G } & \text { Meeting Observations . } & 131\end{array}$

$\begin{array}{lll}\text { Appendix H Provider Interview. } & 136\end{array}$ 


\section{List of Tables}

Table 3.1 Principals' experiences and involvement in the cluster

Table 4.1 Features of the cluster indicated by the principals.

Table 4.2 Involvement in other professional development

Table 4.3 Indications from principals of personal and professional benefits

Table 4.4 Tally of contributions to discussion

Table 4.5 Benefits for schools from participation in the cluster. 


\section{Introduction}

The purpose of this study is to investigate an example of professional development in a group of rural schools. Small schools that are located in isolated rural communities are frequently viewed as experiencing difficulties in achieving effective professional development. Principals and teachers in rural schools are often perceived as being isolated from new knowledge and change. Not only are they located away from colleges of education and universities, which are likely sources of new knowledge, they have constraints of time and resources to travel to these centres. Principals of these schools combine teaching and the management of administrative tasks that are similar to larger schools without the same level of financial or personnel resource. They are sometimes limited in their choice of participation opportunities in professional development simply because there are no relieving teachers available in their location to take their class for a day. The need for professional dialogue and collaboration is greater for these principals than their urban colleagues because they often work in schools with no other educators with whom they can interact to gain support and encouragement. Yet, these principals are major contributors to educational quality in small schools.

The study is significant as a large number of schools in New Zealand are in rural areas. Approximately $70 \%$ of small schools (schools with rolls less than 160) are in rural areas.

Research that investigates the effective provision of professional development for rural schools is needed to investigate their capacity to provide quality education regardless of location in New Zealand. Research of rural school professional development provision is scant as, according to Stephens (1984), researchers lack an appreciation that rural and urban schools have different professional development needs. Professional development packages from an external provider do not necessarily fit rural schools. Their needs are not always apparent to those from outside the school. Principals and teachers in similar rural locations can share a common focus for professional development because they have similar needs. Within the sharing and understanding of new knowledge they can overcome some of the deficits identified as originating from their rural settings, such as lack of 
collegial support, opportunities for professional dialogue, leadership, reflection and a relationship with a 'critical friend'.

Isolation from knowledge and change is not always a deficit as technology is increasingly overcoming this, but the physical and geographic isolation of the principal or teacher from other professional people within a small community is still peculiar to many rural schools. When the community actively shares the same goals and vision for their school the whole learning community can move forward together. If the community has no interest or involvement in the school, the principal can easily become absorbed by the demands of the community and isolated from other educators.

Demands on the school as the focus for the community are an extra load carried by the principal and teachers in many small rural schools. This load, which often requires principals to become involved in all manner of extra activities such as sports events, farewell functions, concerts, search and rescue, volunteer fire brigade and local government takes time and energy from personal, professional and social goals.

The Ministry of Education has acknowledged the heavy workload of principals of small rural schools in New Zealand. School Administration Support Clusters have been established since 1997 when a programme was first piloted. The SASC programme aimed to facilitate cooperative and innovative administrative arrangements between schools. It aims to reduce principals' and boards of trustee workloads and to allow principals and boards more time to focus on improving learning. It also aims to assist principals and boards in the effective management of their schools. The programme was offered to schools with rolls of 160 or less students. It included funding and the offer of regional providers to assist schools to form clusters and to ensure that schools used the cluster funds for projects that have the most benefit for them but also work towards the Ministry's priorities. While these clusters were established with a focus on reducing workload they also included an opportunity for participating principals to work on projects. For some clusters the next step was to use these clusters as opportunities for professional development. 
It is not just the isolation but also the size of a school that is a significant factor in the decision to use a model that clusters schools for the purpose of providing effective professional development. By clustering together, schools can create a stimulating, safe environment providing opportunities for socialization, reflection, collaboration and learning, which is not always present in small school settings. The cluster model is constantly evolving, from being organized for such a purpose with Ministry of Education objectives and facilitators to, a voluntary, spontaneous homegrown initiative.

Rural schools that cluster, network, collaborate or simply meet together for the purpose of professional development are using an attractive model for school and personal improvement. Some of the factors identified by researchers as essential to effective professional development can occur because of the collaborative nature of the meetings.

Fullan and Hargreaves (1992) suggest that collaboration rises spontaneously from teachers as a social group. They work together with enthusiasm and results if they are volunteers. They like to work together on their own ideas or on a shared need.

Rural school principals and their teachers meet for many reasons. They do not consider all of these meetings professional development but these meetings can lay the foundation for important professional development initiatives to emerge.

This study began with the researcher questioning effective delivery of professional development packages to schools, regardless of their location. As the coordinator of a contract for the Ministry of Education it was the researcher's responsibility to plan an economic and efficient way to deliver a professional development package for all schools in the South Island of New Zealand that gave new information, demonstrated strategies for teaching and learning and provided for in-school needs based support. When one of the rural schools in the cluster being studied was approached during this contract, their response was to ask if the contract could be delivered to six schools as clustered professional development. This was an unusual but positive request. It enabled the workshop approach to be interactive and for participants to learn alongside colleagues who would continue to be their mentors and support network once the Ministry of Education contract facilitators had left. It was the preferred option for these principals with the practice already well established and accepted. This is the cluster in this study. 


\section{Need for this study}

Research that investigates the effective provision of professional development for rural school principals is needed to confirm that all schools are capable of providing equal opportunities for quality education for children regardless of location. There are many small schools in rural New Zealand with principals facing the same challenges yet there is limited research on professional development provision for rural schools

Research is needed to investigate whether principals of rural schools have specific needs for their professional development. Some principals are both teacher and principal with additional responsibilities to isolated communities as well as to students.

Providers of professional development frequently question the style and effectiveness of the provision of professional development. This study will describe professional development from the perspective of the principals from a rural cluster of schools. This is important because the focus is on the professional development needs, choices and actions of a very vulnerable sector of the educational profession.

Rural school principals meet for many reasons. Not all of these meetings are considered to be professional development by them or by others. The focus for this study is a group of principals who meet regularly with other principals specifically for professional development. They have chosen to participate for a number of years in a model that is continually evolving. This investigation questions how and why these principals of six rural schools use a cluster model for most of their professional development and what factors have sustained it.

The value of this study, which involves interviewing the principals of six schools, and observations of meetings is that it seeks to identify some of the factors that enable a cluster model to evolve. Providers of professional development may use this study to guide their delivery style for rural school principals. The study may also question perceptions about the capacity of schools to provide for their own professional development. 
Chapter One will consist of a literature review of professional development. Chapter Two will outline the characteristics of rural schools and their provision for professional development. Chapter Three will describe the methodology for the study and Chapter Four will report the results. Chapter Five will include discussion of the findings and the study will conclude with the implications of the study and some possible directions for future research. 


\section{CHAPTER ONE}

\section{Professional Development}

The literature review will first define the terms for professional development. It will examine models of professional development to investigate the factors that are currently considered to contribute to successful outcomes both in New Zealand and other countries.. Underpinning this is an understanding that the goal for effective professional development is improved student learning outcome because it is considered to be the best way to raise the academic achievement of students.

Some references included in the review have been located through a literature search based on the key words, rural school professional development. It has been difficult to identify what constitutes rural school professional development. There are many different terms for professional development with different understandings in different countries. Each term has its own way of signaling the intention that new learning and change will have on the participants. Historically, terminology and definitions have changed as new understandings of teaching and learning have appeared and become accepted by educators, researchers and theorists.

Good and Brophy (1984), suggested that professional development occurs when teachers are required to critically examine their own teaching practice while seeking feedback from others. They saw the teacher controlling each step of the programme. Professional development, according to Smylie and Tuermer (1995), is a systematic attempt to bring about progress towards an articulated end that requires long term systemic individual and organisational change. In the United Kingdom professional development is understood to be concerned with membership of a professional community and therefore determined collectively rather than individually (Nixon, 1992). Professional development, is a term that can be used to describe both individual and group change.

Educators in New Zealand, use the phrase, 'professional development ' to refer to any form of in-service training or study that is offered to teachers either individually or a group, 
sometimes with a qualification earned at the completion and /or for school improvement. Frequently this is achieved with the support of an outside facilitator.

When Buchanan (1993), who is one of the few commentators who focuses particularly on rural schools and professional development, asked the staff of six New Zealand rural schools for definitions of the term, professional development their responses were all variations of “ Being helped to grow in my profession. Gaining confidence, sharing experiences, being kept up to date with recent curricular developments”(p.24). Teachers generally believe, that participating in professional development will help them become better teachers. Qualifications are not included in the comments from the teachers in Buchanan’s study.

The term, 'in-service 'identifies the status of the participants in professional development. It is used when registered teachers who are employed in schools receive extra training, information or learning. Traditionally in New Zealand schools, in-service professional development has been provided by outside services such as an advisory service attached to a college of education.

Another related term,' pre-service ' is used by educators, in New Zealand, when referring to trainee students who have not graduated as teachers and are receiving training. Their training is usually managed on campus or by distance from lecturers based at a college of education or education department in a university. Lecturers working with pre-service participants do not necessarily provide in-service professional development. The two learning opportunities are usually kept quite distinct. This is the usual practice in Australia too, as Free and Nolan (1988) found that teacher training institutions rarely followed their graduates into the workplace to participate or contribute to their professional growth.

'Staff development ' is a term used in New Zealand specifically when a school decides to move in a certain direction and provides on site, whole school staff development. This provides consistency; shared understandings and responses to the discrete needs of the school, teachers and students. This can be facilitated by staff members or by external agencies such as the Ministry of Education, advisers from colleges of education or private educational consultants. The same term, 'staff development ' was used by an Australian 
lecturer Spencer (1994) when describing strategies for achieving change through teacher development in rural schools.

Other terminology such as 'school improvement ' was successful in the search in providing examples of school based professional development, particularly in the United Kingdom. A definition for school improvement widely used and understood in the UK is:

"A systematic sustained effort aimed at change in learning, conditions and other related internal conditions in one or more schools, with the ultimate aim of accomplishing educational goals more effectively” (van Velzen, Miles, Ekholm, Hameyer, \& Robin, 1985 p.48). There are many factors that contribute, over time to school improvement but the ultimate result is reaching educational goals.

A leading author on the subject Hopkins (2001) uses the phrase 'staff development' rather than 'professional development'. Staff development, includes training of staff so that school improvement can occur. Hopkins, describes school improvement not as a 'quick fix ' effort but as a 'journey ' with an emphasis on capacity building, teaching and learning. At the heart of effective school improvement, most authors believe, there will be evidence of powerful and effective learning experiences for students.

After exploring the range of terms currently in use, the term 'professional development' will be used by the researcher in this study, to describe activities in which principals or teachers participate individually or in groups for personal and professional growth. There is an assumption that this growth will be associated with change, first of all in understanding and then over time in practice.

\section{Models of Professional Development}

In New Zealand the nature of professional development has changed dramatically since Tomorrow’s Schools reforms. Prior to 1989, much of the professional development offered to teachers was initiated and organized by the regional offices of the Department of Education. Typically, schools received invitations to nominate teachers for a given number 
of places at courses and seminars. This achieved individual teacher development for a target group of teachers.

After the review, CRRISP (Curriculum Review Research in Schools Project 1987), the then Department of Education's major teacher development projects, were provided via tendered contracts and a new model emerged. The model used for these contracts, according to Burt and Davison (1999), in their history of New Zealand curriculum reform, comprised a series of seminars interspersed by facilitator visits, to provide on-going inschool support of the change process. The intended outcome was to empower principals to work cooperatively with their staffs and boards of trustees to identify curriculum needs and to plan, implement and evaluate a school-wide teacher development programme that met their needs. The recommendations from CRRISP had helped to change professional development approaches from a focus on an individual representative from a school accessing the new knowledge to a whole school approach.

At present in New Zealand there are three ways that staff development and professional development can occur for teachers. The terms 'staff development' and 'professional development' are commonly used to describe the three forms of learning and, although quite distinct all can contribute to improve learning outcomes for students (O’Sullivan, 2000).

The first example, described as 'direct funded contracts' are led by an adviser who may be directed by the Ministry of Education to work with targeted schools There may be limited consultation or choice for the principals and teachers involved in the targeted schools. In the past many professional development designs, such as those delivering Ministry of Education contracts, as described by Burt and Davison (1999) assumed that direction was from an outside expert, such as an adviser. The move to empowering the principal, acknowledging that he/she has knowledge and identifying him/her as the key person in the change process in a school, is a significant recent development in the delivery of these contracts.

Secondly, schools may request support as a result of a decision made by the principal/board of trustees (with or without consultation with all teachers), from an Advisory Service, 
tertiary institution or private provider for an identified need based on the school's vision for change.

The third option is when teachers seek additional qualifications or follow a personal interest. This is personal professional development and, according to O'Sullivan (2000), it is crucial that it occurs for reasons of morale and professional status.

The Ministry of Education has extensively evaluated direct funded contracts that are coordinated by colleges of education. Poskitt (2000) found cluster arrangements; particularly in rural areas seemed to enhance greater sharing of expertise, resources, administration and access to providers.

Different models of professional development can produce different outcomes. When he visited six rural schools in different parts of the world, Spencer (1994 pp.42-45.) found a variety of ways that professional development is planned and delivered. He found that the six different models generated different outcomes.

The first perspective came from Israel, which he called The Laissez -Faire Model: 'I did it the hard way-why shouldn't you?' The outcome was that principals and management refused to admit any responsibility for the provision of staff development.

The second perspective was called The Deficiency or Error-factor model or 'Let's assess what is wrong and rectify it.' This process was found in Scotland and Wales .The two outcomes were resentment and fear, which pervaded the schools where the appraisal process was being established. Rectification to gain competency was through attending courses outside of the school.

Perspective three was only found in Australia and was called The Protagonist or Conflict Resolution Model. Every group was perceived as a potential conflict situation. This negative attitude ensured administrators were always apprehensive and planning to avoid conflict instead of developing knowledge, understanding and resolving conflict. 
In the fourth perspective called Employer-Prescribed Development Model, found in County Durham, Spencer believed the professional maturation of the school's own resources were given no recognition at all.

In Scotland Spencer found Perspective Five, which he called Problem Oriented Model. The emphasis was on problem solving to manage the specific in-school problems. This principal found that, for basic staff development and initiating a professional maturation process, she had all the resources she needed in the school.

The last perspective called Facilitative, Needs Based Model, similar to the Problem Oriented Model, also suggested that all the resources needed for staff developmentattitudinal, experiential, knowledge and techniques were in the school. Spencer claimed he had not seen this pursued with any determination but said that colleagues have advocated for years that there was a vast untapped pool of knowledge, skills and experience in every school.

There has been a growing expectation from both providers and recipients of professional development that their efforts should result in improved outcomes for the students, teachers and their schools. (Hill, Hawk \& Taylor, 2001; Joyce \& Showers, 1996; McLaughlin, 1990; Sparks \& Hirsh, 1997). Researchers Newman and Wehlage (1995) coordinated a national study to find the common characteristics of schools that were providing a continuous learning environment for both students and teachers. They discovered that schools that were most successful with improving student learning outcomes were those where teachers pursued a clear and shared purpose for all learning, they engaged in collaborative activities to achieve that purpose and took collective responsibility particularly for their students' learning. It has also been found that when professional development is linked to school improvement and change, teachers are more likely to modify their practice. Hopkins, Ainscow and West (1994) indicate from their research that school improvement is about working with rather than working on schools to raise student achievement by focusing on the teaching-learning process (p.4).

The source of knowledge about teaching influences how professional development models are organized. School-based professional development can be categorised according to 
Hoban (1997) into three groups: outside -in models, inside-in models, and inside-outside models.

The first example, outside-in model draws upon knowledge that has been generated by others for teachers to use in their practice. It supports the conventional role of educational researchers who regularly work outside schools and produce knowledge for teachers inside schools (Lytle \& Cochran-Smith, 1994). A rationale for this model is that teachers tend to use existing practice and need to be informed to provide alternative perspectives on teaching and learning through attending staff development training programmes (Hatton, 1988).

Showers (1988) considers that each of the three models has advantages and disadvantages but has some specific thoughts about the outside-in model that uses training programmes. Five components are identified for a successful programme. First the programme should include an exploration of theory that includes opportunities for discussion, readings or lectures to assist participants to understand the ideas being presented. Secondly there will be demonstrations or modelling of the new ideas using video or live observations that are integrated with the explanations of theory. Thirdly, there should be provision for the practice of the skills under simulated conditions to approximate the workplace allowing for at least 20 trials depending on the complexity of the task. There should be feedback from peers or experts following practice. Fifthly, there should be the provision of coaching in the workplace following initial training for support and collegiality during the learning process. Although successful training programmes probably do include these five components Hoban (1997) says they do not take into account existing practice and belief of teachers.

The second example, described by Hoban as the inside-in model, encourages individual teachers to take responsibility for their professional learning. A key aspect is personal reflection to assist teachers to become aware of how they understand their practice.

The four main examples of the inside-in model, described by Sparks and Loucks-Horsley (1990) are:

(a) Individually Guided Staff Development. Examples include teachers experimenting with new instructional strategies that they have devised, visiting other classrooms, studying new materials and other tasks where they are self directed learners. 
(b) Observation/Assessment Staff Development Model which involves teachers working in pairs or buddies to observe and provide feedback to each other.

(c)Development/Improvement Staff Development Model which is a collaborative model when teachers share ideas about a problem that depends on a variety of perspectives for success.

(d) Inquiry Staff Development the purpose of which is for teachers individually or collectively to learn by formulating their own questions, to conduct research by collecting and analysing data. Sparks and Loucks-Horsley (1990) list three assumptions that underpin this model. They refer to the teacher as a proactive learner with the source of knowledge about teaching being within a teacher's experience:

(1) Teachers are intelligent, inquiring individuals with legitimate expertise and important experience

(2) Teachers are inclined to search for data to answer pressing questions and to reflect on the data to formulate solutions and

(3) Teachers develop new understandings as they contribute to and formulate their own questions and collect their data to answer them. (Sparks \& Loucks-Horsley, 1990, p 243)

The third example described by Hoban (1997) is the inside/outside model. This model includes two major aspects of teacher learning, personal reflection by the participants and the introduction of alternative views from outside. The model includes shared control of the agenda and the contribution of a rich variety of ideas. It can include participation with preservice and practicing teachers and /or links with university and college of education lecturers, researchers and educators from other institutions. An example of a large-scale version of this model is The Learning Consortium, which included four school districts and two universities around Toronto, Canada (Fullan, 1993). The focus was on the redesigning of both teacher education and the practice of teaching. (Cochran-Smith \&Lytle, 1993; Grossman, 1994; Yinger \& Hendricks, 1990) A much smaller example of this described by Free and Nolan (1987), involved five rural Australian schools and the Armidale College of 
Advanced Education. Their focus was to trial a model for effective professional development delivery. It was an initiative that followed graduates from pre-service into their workplace.

When the inside/outside model has a focus on the professional development of teachers, it tends to involve participants in researching, discussing and writing about their investigations for both personal and public knowledge. An example of this approach is the Project for Enhancing Effective Learning (PEEL) in Australia. (Baird \& Mitchell, 1987) There are interactions between the teachers who have generated the knowledge and alternative perspectives introduced by university based educators, parents or students.

Hoban (1997) saw strengths and weaknesses for all models and claimed all professional development models are designs for learning that should support teachers in the process of knowledge construction in a positive learning environment. When principals and teachers are actively involved and support each other in the process of gaining new knowledge that they believe is relevant there will usually be evidence of it in their practice. Collaboration, that includes both giving and receiving knowledge and support is not easy to achieve for principals and teachers in small rural schools.

Friend and Cook (2003), who have written extensively on the value of collaborative approaches within schools, claimed that staff may learn new skills but are not likely to implement them without collaborative relationships with colleagues who support their efforts. Furthermore, Darling-Hammond, Cobb and Bullmaster (1998) argued that teachers' abilities to create, produce knowledge and make decisions shaped their practice.

For some teachers collaborative approaches also encouraged them to take new roles as leaders and mentors. They maintained that professional development that rarely draws on teachers' own experiences or defines teachers' roles makes it difficult to accomplish the purpose of the professional development. Many initiatives take little account of the teaching context and rarely distinguish between rural or urban schools’ needs. Professional development provision, should consider teaching context, as a rich source of problems for stimulating learning through emphasising collaborative problem solving, planning, teaching and decision-making. 
The conventional view of professional development, claimed by Lieberman (1995) as a transferable package of knowledge to be distributed to teachers in bite sized pieces needs radical rethinking. Many teachers have been told often enough that other people's understandings of teaching and learning are more important than their own and that their knowledge gained from daily work with students is of far less value.

So where does the expertise or knowledge come from in good professional development? Hargreaves and Fullan (1992) believe that teachers do not learn by themselves instead they learn from contact with other people who are knowledgeable about and have experience of teaching and learning. Teachers learn from study, from their own students, from each other and from reflective practice.

When professional development packages are delivered by outside providers there are important issues for consideration. Principals of rural schools especially, need professional development that acknowledges their skills as well as their specific needs. Some of these needs are to do with their professional isolation so the principals are looking for opportunities to work collaboratively, to engage in professional dialogue and because they are working alone, to be supported in the construction of new knowledge.

\section{Collaborative Learning Communities}

Learning with other learners is a strategy that works well for students and this has been explored as a professional development tool for teachers. There are several terms such as educational reform networks, partnerships and collaboratives, which are terms used by Lieberman (2000), to describe formal groups that are organised around the interests and needs of participating teachers in some states of the United States of America.

Learning in networks has been occurring for teachers for many years in America and the following description helps to show the advantages of such initiatives. 
Networks have become a way of engaging school-based educators in directing their own learning and by allowing them to sidestep the limitations of institutional roles, hierarchies and geographic locations, encouraging them to work together with many people outside their schools. (Lieberman \& Grolnick, 1996, p.292)

As an organizational form they have become increasingly important to the reform movement in American education. Some years ago, Parker (1977) studied over sixty networks that were in existence prior to 1977. His observations showed that members had a sense of being part of a special group or movement. He identified the following five key ingredients from his study:

(1) A strong sense of commitment to the innovation

(2) A sense of shared purpose.

(3) A mixture of information sharing and psychological support.

(4) An effective facilitator was essential.

(5) Participation was voluntary with participants having equal status.

Building on these insights some years later Lieberman and Grolnick (1996)) studied sixteen networks that had been set up by participants to direct their own learning in America. Some networks studied evolved from conversations, courses or consultants. In each case the network existed because of a compelling reason. Fifteen of the sixteen networks received significant or complete funding from private or corporate foundations. This made some networks vulnerable as the fund-holders felt they were entitled to exert influence on the direction of the network. Other networks found the need for assessment to satisfy fundholders' needs constraining, as results were often indirect and difficult to evaluate.

Lieberman and Grolnick (1996) describe tensions that occurred consistently within all the sixteen networks in their study. The purpose of the network needed to be compelling enough to engage the participants. If it was not relevant then participants did not keep involved. A second tension was concerned with using inside or outside knowledge. While most networks tried to do both, the question was, who knows best what the participants need? What should be included on the agenda? Some networks were loose and tensions appeared when connections were not made between members and leadership. All networks were flexible but found difficulty when they 'grew up' and wanted to convene retreats and 
conferences. When networks began recruiting new members the need for membership to be of like -minded participants became an issue.

Networks can also be described as collaborative learning communities that developed to support and sustain teacher learning over time. Their creation has not been as a result of the location of schools but rather because of the outcomes from the organizational conditions that allow teachers to participate in their own development. Meier (1992), when describing the organizational conditions that support collaborative learning communities stated,

At the very least, one must imagine schools in which teachers are in frequent conversations with each other about their work, have easy and necessary access to each other's classrooms, take it for granted that they should comment on each other's work, and have the time to develop common standards for student work. (Meier, 1992, p.602)

Organisational structures, such as networks, clusters, learning communities, professional development schools, partnerships and school improvement collectives provide more than mere support for teachers' acquisitions of new skills or knowledge (DarlingHammond \& McLaughlin 1995).

A number of writers discussed how communication between participants in a learning community could reverse the isolation felt by teachers regardless of the size or location of the school. The idea of bringing schools together to achieve, 'sustained teacher learning over time’ (Lieberman, 2000) is supported by technology that has changed the way people communicate, work and learn. (pp. 221-227)

The notion of learning together with other teachers within a school or with other schools within a cluster have many advantages. (Birman, Desimore, Porter \& Garet, 2000). They see collective participation contributing to a professional culture where teachers develop common understandings of instructional goals, methods, problems and solutions. However the challenge for those involved with collective staff development, as teachers or providers, is to remain positive to changing needs and to use reflection to sustain continuous development. (WEB Research, 1997). 
For some principals and their schools, it is a challenge to support change, make learning effective and develop a community of learners. The issues are with balancing the needs of the school to comply with ministry of education requirements and the personal and professional needs of individual teachers as they move through their teaching careers and life experiences. Bolam (1987) found that teachers have distinct developmental needs, like all learners, linked with the stages of their particular personal professional growth.

Researchers, Birman, et al., (2000), Clark (2000), and Lieberman (2000) suggest that life age and career cycle are significant to teachers' participation in professional development and change.

According to Hopkins (2001), the school's capacity for school improvement should be considered from the outset because, without a clear focus on 'capacity', the school will be unable to sustain improvement. Bolam (1990) warns that teachers can become little more than, 'bureaucratic functionaries' (p.164) because they are frequently kept too busy complying with educational reform to engage in meaningful professional development and contribute as informed professionals. Burt and Davison (1999) found that not all schools have reached the same stage when professional development contracts end. Schools can be left at different stages of change.

Teachers cannot move rapidly from one style to the other with confidence unless they have been part of the change decision and have a shared commitment to the idea and purpose. (Parker, 1977). The development of collegial support is not simple, as the creation of collaborative partnerships is part of a developmental process. Darling-Hammond, Cobb and Bullmaster (1998) acknowledge that a struggle exists if there is an expectation that staff will move easily from rigid top down structures to collegial participatory approaches to staff development.

When teachers as a group or a community manage their own professional development, they make decisions based on a whole school team approach. In order to do this, good communication, interpersonal relationships and a climate of support need to be part of the culture of the school. While teachers are usually alone in their classrooms the outlooks and orientations of their colleagues heavily influence their classroom practice. The relationships between teachers are considered to be amongst the most educationally significant aspects of 
teachers' lives and work. This is not a recent discovery, as it was a point made over seventy years ago by Waller, (1932) when he observed that what goes on in the classroom cannot be separated by the interpersonal relations that happen outside it. Yet there is a pervasive culture of individualism among teachers, which Hargreaves (1983) suggests might be characteristic of the entire occupation. He found that some efforts at collaboration could not extend beyond the routine, advice giving, and planning units of work, special events or material sharing.

Like Hargreaves and Fullan (1992), Lieberman (2000) and others have found that good professional development is effective when it is collaborative. This means that teachers have collaboratively collected data to identify need then designed their learning experience so that it is relevant, required and able to be sustained. (Berman \& McLaughlin, 1978; Little, 1993; Sparks, 1996). Good professional development acknowledges that teachers have specialized skills and when they are in a supportive environment it enables reciprocity to occur. (Friend \& Cook, 2003; Fullan \& Hargreaves, 1996; Fullan, 1999).

Estebaranz, Mingorance and Marcelo, (2000) described collaborative teacher directed approaches to providing staff professional development that have existed in Andalusia since 1983. They were called permanent seminars and the model was adopted as a selftraining modality for teachers. The aim was to enable teachers to manage their whole training independently and to, “ Give innovating teachers their head in setting up teams for renovation in teaching” (p. 124).

Estebaranz et al. described permanent seminars as a continuing system of selfdevelopment and reflection in the practice of teaching. The permanent seminar approach did focus on the teachers' own learning and did not view teachers as passive recipients of other people's knowledge. It showed that from the outset teachers could lead and initiate their own professional development with adequate funding and direction. This attempt to establish a general framework of action and coordination in the ongoing training of teaching staff aimed to be a self-development activity that was a natural continuation of pre-service training. The teachers used their classroom teaching experiences and training through teacher-to -teacher interchanges. It included teamwork for communication and the 
sharing of experiences in educational tasks and seminars emerging from the team with close links to the reality of the classroom.

The permanent seminars in Andalusia were considered a necessary connection between the acquiring of new knowledge, and the analysis and interchange of experiences. They were considered to be a meeting place for teachers with different backgrounds and experience, allowing reflection and interchange of knowledge to take precedence over practice. This approach not only focused on teachers' learning and teaching but also the impact that teachers’ new knowledge had on classroom practice and student learning:

"They are a form of study, analysis and reflection on a topic chosen by the teachers themselves to acquire a deeper knowledge of that topic.” (Estebaranz, et al. 2000 p.125).

This reflects Clark's (1992) thinking about teachers needing to view themselves as professionals. The focus should be on the teachers' strengths so that they are not constantly humiliated by an agenda tied to perceived weakness, which Clark (1992) found are presently characteristic of self-directed professional development practice.

Blackmore (1999) suggested that teachers needed to re-define the profession of teaching and commit to professional renewal not just professional development. Professional renewal is more than taking responsibility for a classroom or school; it is a professional commitment to the field of education, both theoretically and practically lifting expectations beyond self-interest. Sometimes, in extreme situations such as Schmuck and Schmuck (1990) found, when teachers and administrators have worked in the same place for 15 to 20 years, incentives need to be put in place to help them move from their old, and frequently hierarchical patterns .

Principals, as leading learners, need to use reflective practice to review and revisit their own skills so that they can change and encourage others to do so too. (Day \& Bakioglu, 1996; Reeves, Mahoney \& Moos, 1997; Sergiovanni, 1992) Reflection needs a group and, while some principals observed by Day (2003) were members of informal networks of peers, others were part of more formal networks and organized their own professional development. There are distinct challenges for a principal who reflects alone because there is a limit to what information can be disclosed. Reflection is considered to be essential for 
effective leadership. Reflective principals are able to distance themselves from their everyday worlds. They are open to influence by others while maintaining their effectiveness as leaders:

Effective leadership is as much about developing self as it is about capacity building in others and such effective leadership requires an intelligent head and an intelligent heart. It requires principals to engage simultaneously in reflection in, on, about and for the action in each context in which they work. (Day, 2003 p.43.)

According to Dimmock (1995), schools are essentially places for all to learn with the student at the centre of its operation and with teachers who see themselves as learners too. Frost, Durrant, Head and Holden (2000) and Stoll and Fink (1996) found that there are benefits when students are learning alongside adults because both students and teachers become life long learners. The same strategies that are advocated for students who are learners should be available for teachers. If improved student learning outcome is the aim for professional development then the same outcome should be achieved for teachers.

Most of the research discussed has been from outside New Zealand. A study from New Zealand supports the findings from overseas studies. Hill, Hawk and Taylor (2001) found that professional development plays a vital role in ensuring a school is a vibrant learning community. The study showed evidence that quality professional development happens onsite with collegial support. Professional development needs to change professional practice with a focus on improving student learning outcomes and that funding is a significant issue for all professional development models.

Parsons (2000) included some recommendations in another New Zealand study about teacher ownership and links with the world of teaching. According to Parsons (2000) there are four identified attributes of quality professional development. Firstly, links between theory and practice are clearly established. Secondly, professional development must be relevant and owned by teachers through focusing on their real and daily concerns. Thirdly that it must involve situated learning that is located in the real worlds of teachers. Lastly, that professional development will ultimately lead to a change in teacher knowledge, beliefs and expectations, so that modification and transformation of pedagogical practice occurs. 


\section{Summary}

A survey of the literature confirms that the principals of small rural schools often experience difficulties in achieving effective professional development. Clustering with other schools enables them to interact with other educators and to overcome some of the challenges of working in isolated locations. The nature of professional development has changed in New Zealand, with research showing positive outcomes for cluster arrangements for the delivery of professional development in rural areas.

The source of knowledge influences the outcomes for effective professional development. Hoban (1997) saw strengths and weaknesses in each of the three models that he described as outside-in, inside-in and inside-outside models. Most educators would agree with Hoban but the important issue is that there is a choice of different models. One size does not have to fit all schools.

When principals and teachers worked collaboratively constructing knowledge and sharing results with those 'inside and outside' there was a greater chance of sustained change occurring. Many researchers have indicated that teachers learn from each other and from reflection on daily work with their students. (Hargreaves \& Fullan, 1992; Lieberman, 1995; Sparks \& Loucks-Horsley, 1990) This is achievable, when time and opportunities for this specific focus, are set aside. For the principals of rural schools this is often hard to achieve but necessary for them and their school. 


\section{CHAPTER TWO}

\section{Rural Schools and Professional Development}

Following on from the literature review, this chapter will focus on how rural schools can meet the challenges of accessing professional development through cooperation with other institutions, through technology and through clustering with similar schools.

Rural schools are considered to be different from urban schools mainly because of their setting. Often they are small schools but there are small schools in urban settings too. Many researchers feel that it is more than location and the size of the schools that sets rural schools and their teachers apart. There are examples of urban larger schools initiating and implementing their professional development but it is harder to locate examples of small rural schools working in this way. Examples from the United States of America and Australia show that, even when recent innovations such as technology support professional development in small rural schools, the challenge is ownership by the school as well as the community of the process for accessing the new knowledge. (Birman et al., 2000; Clark, 1992; Darling-Hammond, 1999; Fullan, 1985; Lieberman, 2000; Schmuck \& Schmuck, 1990).

Rural small schools generally service isolated, small and even insular communities. They provide a focus for community activities and contribute greatly to the social, cultural educational and sporting life of the community. Without the school many communities would cease to exist. (New South Wales Teachers' Federation, 1987) When rural small schools service such communities, the isolation impacts on the teachers by making it difficult to engage in professional dialogue or access support systems that are more readily available to larger schools. According to Free and Nolan (1988), this slows curriculum implementation and professional development of staff.

One way of addressing these issues is demonstrated by a pilot venture in 1987 between Armidale College of Advanced Education and members of a small school cluster. Together, 
they developed a cooperative programme for professional development. Lecturers and teachers from five small schools chose to focus on pupil evaluation of spelling, reading and mathematics. School development days were held and members reported back on trials. Free and Nolan (1988) found the major strengths of this model were that decisions and activities had been based on identified needs and that cooperative decisions were translated into practical application in all the schools.

Technology was expected to remove the 'tyranny of distance' for remote rural schools but sometimes there are still challenges to overcome before there is any evidence of benefit from the considerable investment of time and money. Bowie (1996) described the frustrations of a rural school in Australia when attempting to access professional development through computer networks set up for that purpose.

There were three main problems encountered connecting the school to the Internet included:

(a) The cost of access as communication problems arise from the geography of remote areas,

(b) The lack of expertise available to staff, and

(c) Justifying the expense of technology within the community.

Bowie explored the relationships between technology, distance and the community. While it was found that technology could reduce the tyranny of isolation and remoteness in order to maintain and benefit from change, isolated communities needed support to understand the changes being introduced. They needed to share the experiences, so that they could retain an essential level of shared meaning with their children.

This is a rapidly evolving technology and many people are computer literate but not always information literate. Support is needed for the staff and students to learn the new technology and time is a problem in a small school where the administrator has a full teaching load. There is also demand on the staff to develop understanding within the community of the importance of this communication form and to justify why it should be a priority. Use of technology needs pedagogically sound theory to underpin it. Sorting out relevant professional development which is informed about the needs and culture of small rural communities and which will support change and 
develop effective teaching and learning strategies is a major challenge for the staff of this remote school (Bowie, 1996, p. 70).

The notion that technology can support schools to support their communities is an important development. Some researchers see the potential of professional development for rural schools as a change agent for the communities that they serve:

“ Rural schools can function as information resources for community development, directly and indirectly support economic development and make real contributions to the physical and cultural health of communities” (Nachtigal, 1994, p. 145).

A paper presented to the Australian Association for Research in Education by Cocklin (1997) examines one rural school, Rana Primary. The purpose of this study was to investigate the way a 'learning community' can allow for the interchange of ideas between the community and the organisation. He saw that, in order to avoid imposing the 'organisational model' the outside organisation needed to reinterpret it's role in view of the educational context and goals of those in the learning community. One of the dominant themes found by Cocklin, when he investigated this rural school, was the pride that the community had in their school. He found that past pupils attended functions and showed a sense of allegiance and ownership. He found the ongoing contact with their school common to all generations within the community and this included some expressing strong opinions about the buildings and even the location of the new library ' being too close to the road.' The small size of the school contributed to a family concept for the whole school community. Many parents commented on how their children benefited from daily contact in the classrooms and playground with their siblings, friends and family members. Parents and children who were interviewed considered interpersonal relationships to be strongly developed. The size of the school was the reason that one parent felt he could have a say and be informed with how the school ran. This principal encouraged an attitude of involvement and created opportunities to maintain close relationships with the students both in the classroom and playground. In his interview he also considered that the multiaged context allowed for teaching to stages rather than age grading. Small rural schools are capable of providing quality learning environments for their students. Many parents choose small rural schools for their children because they believe that the needs of their children will be met in such settings. 
Rural remote schools have their own culture and also inherent problems related to change that sometimes generate tensions within the community. There can be a mismatch of expectations for student achievement between the home and school. Children and their parents often display low aspirations because their community defines their world. For many rural students, learning experiences at school, particularly with technology widen their horizons and help to prepare them for the complex world that exists beyond their community. Bowie (1996) found that while technology was not seducing the community it was gradually invading the community through the children. Some parents felt that they did not need technology such as computers in their lives but despite this their children were gaining skills and knowledge far beyond the understanding of their parents. Some parents felt threatened, disempowered and even betrayed by the resulting changes.

The notion that change initiated as professional development for teachers has implications for the community was also reflected in an American study by Schmuck and Schmuck, (1990). This study found that although the community participated in some events at the school they did not engage in discussions about teaching and learning. Small-town schools, perhaps more than their urban counter-parts, bring citizens together and enhance a feeling of community identity, but what is sorely needed," is a fresh democratic perspective on what is possible and desirable in the school.” (Schmuck \& Schmuck, 1990).

In New Zealand schools, changes brought about by Tomorrow's Schools (Lange, 1988) have resulted in parents being directly involved in the democratic management of schools. In remote communities the school can be the heart of the local community, the source of knowledge, social contact, leisure activities and learning for everyone.

However, although the school and its community's survival are based on interdependence, the focus of change must go beyond what small-town educators can initiate by themselves. An Australian study by Blackmore (1999) warns that self directed home -grown professional development can become parochial and mediocre unless there is involvement with other professional leaders and new knowledge. For Spencer (1994), getting professional development right for rural schools includes three steps. First the exchange of skills within the school and the community and then the second step moving to 'glean' 
from other schools, other sources and then finally through a facilitative process, establish, expand, enhance and even embellish the 'empowerment'.

Research literature on rural schools tends to focus on issues of isolation and not on the professional development needs of the teachers and principals. Stephens (1984) claimed that this is partly because the differences between rural and urban schools have never been acknowledged. Other reasons, he claimed, are that the subject has limited appeal to the academic community, the small number of professionals who devote careers to continuous rural education, little networking between professional and research communities and lack of funding. This will not improve until studies of rural schools by the academic community elevate the status of rural schools. Stephens claimed that rural schools are superior because of greater individualized instruction, inter-organizational collaboration, effective leadership, community involvement and local control. These themes, suggested by Stephens, for research set rural schools and their needs for professional development apart from urban schools.

Fullan (1985) suggested that the issue of whether rural and urban schools required different in-service programmes should be investigated. Huberman and Crandall (1983) found that rural districts needed more help to find out about available innovations and more assistance with training because they did not have the district staff like urban schools. It was expected that different approaches would be required. There was some evidence though,that once the process was initiated rural schools were easier to work with because they were smaller and had established staff interactions necessary for success.

Some years later, when Spencer (1994) was questioned whether teachers and administrators in rural areas required a different approach or different content to their urban counterparts, his answer was 'no'. He did however, identify some specific characteristics of rural schools. Firstly, he found that the school in a rural community was the most secure and the most cohesive of all community organisations. Secondly, isolation was a fact for rural schools. Buying 'in' training or resources is expensive. Small schools have a small budget so if teachers or principals need to travel 'out' for professional development they may only be able to afford a part of the package or limit their participation. The most important factor for Spencer (1994) was that the professional development was immediately applicable in 
situ. He saw the school and community in rural areas as inseparable as they share the same world. Teachers live and work in the same world as their children and often cannot separate their life during school hours, from their life out of school hours. For some professionals, the rural school is a stepping-stone to bigger things, but for others it becomes a shared culture that they embrace. It is also a stepping-stone for children who deserve the very best education from the most professionally developed and equipped personnel possible.

Improved student learning is an outcome from effective professional development provision for teachers and principals regardless of their schools' locations. The very best education should be available to all children through getting professional development right for their teachers and principals.

\section{Summary}

Principals of rural schools have specific requirements from their professional development that includes learning from each other and reflecting on their practice both as teachers and principals of a community of learners.

Technology is overcoming some of the challenges of isolation for principals in rural schools but there are frustrations with the expense of repairs and because of location, the lack of expertise and ongoing training.

When rural schools cluster for professional development they are able to use group processes such collaborative problem solving, group reflection and shared project development. There are increased opportunities for leadership, mentoring, professional dialogue and debate. The need for collegial face -to -face contact is particularly significant for principals who work in isolated schools.

The rural school has its own culture and is the focal organisation through which many other community events are linked. Professional development for principals and teachers in rural schools has immediate implications for the community. This is a significant difference 
between rural and urban schools and, while researchers acknowledge the differences they do not suggest that rural schools need different professional development, rather professional development that is based on their needs

\section{Research questions}

The framework for the specific research questions was based on a study of a professional development model, reported by Estebaranz, Mingorance and Marcelo (2000) in Andalusia. The permanent seminar model is a form of study, analysis and reflection on a chosen topic. Like the cluster model, funding was received for projects and outside advice and support was available when the teachers thought it necessary. Although the size of the two studies was quite different, the participants in both studies led and initiated their own ongoing professional development within a cluster of schools. The Andalusia study was a descriptive work looking at the internal characteristics of the model, the aims of those involved, the common interests and the individual and collaborative learning strategies being used.

Their fundamental questions were:

What learning can we expect of teachers working in permanent seminars?

What achievements can be considered relevant?

What are the implications for the programmes of professional development of teachers?

This study explores the professional development provision for the principals of six schools that are located in one of the most isolated regions in New Zealand.

The specific research questions for this study are:

Why are the principals of six rural schools using a cluster model for most of their professional development?

How is professional development achieved?

What factors sustain the cluster model? 


\section{CHAPTER THREE}

\section{Methodology}

This chapter first defines the cluster model and then describes the participants in the study and the setting. It then describes the research design and the reasons for using a case study. Finally it explains the procedures used for the data collection, the data sources and analysis. Data were collected from six different sources and they will be described under six key headings which are: the key principal interview, the participant principals' interviews, the questionnaire, historical files examination, observations of meetings and external provider interview.

\section{The Research Questions}

This study investigated why the principals of six rural schools used a cluster model for most of their professional development, how professional development was being achieved and what factors sustained it.

The specific research questions are:

Why are the principals of six rural schools using a cluster model for most of their professional development?

How is professional development achieved?

What factors sustain the cluster model?

\section{Defining the cluster model}

Clustering schools for professional development for a specific curriculum focus happens quite frequently in New Zealand. Providers of professional development encourage this approach and are often instrumental in setting up clusters by grouping schools, facilitating

meetings, choosing venues and directing programmes. Clusters can comprise a mixture of 
secondary, intermediate and primary schools, whose teachers meet for a specific curriculum focus, for a specified time frame. Location can be a factor for the selection of schools, but often the professional development provider will cluster schools according to the provider's choice. Some clusters exist for the duration of such a programme while others keep evolving and continue for other reasons. The cluster model in New Zealand is similar to organisational structures described as networks, learning communities, professional development schools, partnerships, school improvement collectives and collaboratives in the United Kingdom, United States of America and Australia. The focus for this study is of particular interest because the participating principals, not outside providers, have chosen the model for their professional development needs.

\section{Participants}

The principals who have been chosen to participate in the study have formed a cluster and meet voluntarily for regular professional development. The six principals are aged from early thirties to late fifties. As shown in Table3.1, four have been teaching for between twenty and thirty years while the other two have been teaching nine and ten years. One principal has sixteen years experience as a principal and another has eight years. The other four principals have four years, two years, one year and the fourth, nine months as

principal. The participant who has been principal for nine months had been participating with the cluster as the deputy principal but has recently been appointed as principal. Two of the principals are women and four are men. One male was acting principal while his wife was on maternity leave but otherwise all other principals have permanent positions. 
Table 3.1 Principals’ experience and involvement in the cluster

$\begin{array}{lcccccc} & \text { K } & \text { E } & \text { P } & \text { M } & \text { C } & \text { S } \\ \text { Years' teaching } & 30 & 29 & 23 & 20 & 10 & 9 \\ \text { Years' principal } & 1 & 16 & 8 & .75 & 4 & 2 \\ \text { Cluster involvement } & 1 & 5+ & 2-5 & 5+ & 2-5 & 2-5\end{array}$

All participants have taught in other parts of New Zealand and some have experience of working in urban as well as other rural schools. All have classroom teaching responsibility with some release time for administration. Four of the principals in this study live in schoolhouses beside their schools. One lives on a farm in the school community and the other lives a half hour drive away in another community. This means that five of the six principals are living and working in their school community.

\section{The Setting}

The schools are located in a scenic part of New Zealand, which attracts tourists and sports people. Numbers of families live for part of the year in the region and send their children to local schools while they are in New Zealand. Others have chosen to live permanently in the region and become part of the school community. All of the schools have a mixture of children from old established families and from new arrivals. There is a mix of races but not a high proportion of Maori or Pacific Island students in any of the six schools.

Two schools in the study are sole charge. The other four schools do not fall into the remote or isolated category but are categorized as small rural schools. They have two, three and five teachers while one is an Area school with a primary and secondary school with a total 
of eight teachers. None of the schools in the study has more than 300 students. This is not unusual, as only 174 of the 720 schools in the South Island of New Zealand have more than 300 students.

Two schools are considered to be the most remote schools in New Zealand other than the Chatham and Pitt Island. They are located one and a half hours drive away from their next closest school. The roads are mostly gravel and follow the coast with bush on one side and deep water or cliffs on the other. Travel is slow and hazardous. In the summer the dust affects visibility. In the winter the roads tend to slip into the sea or the trees and cliffs slip onto the roads. Both remote schools have school buses but a significant number of children in these schools come to school by boat. Some students use a combination of transport such as farm bike, boat and school bus. Students, principals and parents often use boat access to attend sports' days, camps or cluster meetings. Visits to other schools and locations are important breaks from isolation for both the parents and students but require considerable effort and planning to be safe and enjoyable. Frequently this means that both parents make the trips out while grandparents and other family and friends come along for the ride.

All schools have long histories and have been in existence for at least 140 years in each of the communities. This is significant in rural districts where the school has been perceived for many generations as the focal point for the community, the change agent from where new thinking and direction can originate. This reflects Nachtigal's (1994) findings that "Rural schools can function as information resources for community development, directly and indirectly support economic development and make real contributions to the physical and cultural health of communities” (p.145).

\section{The Research Design}

A single case study approach was used for the investigation. This strategy was chosen because it allowed for a variety of research options such as interviews, surveys, historical document search and observation. It was an attractive option because the study was of a contemporary real life activity, over a specified period of time (the year 2003) with no 
control by the researcher over the behavioural events. According to Yin (1994), the case study is preferred in such situations where more than one strategy is being used but especially when the study is concerned with answering 'how' and 'why' questions. The researcher interacted with the participants in their own natural settings. This helped to view the study through the eyes of the participants, particularly to understand the degree of isolation that some of the principals were experiencing. .

Data were collected from a wide range of sources, both present day and historical, to enable the researcher to draw some conclusions. The focus of the study narrowed as the process moved forward. This has been like the metaphor of a funnel, which Bogdan and Biklen (1992) used when describing the start of a case study as the wide end and the narrowing focus as the study moves along with more directed data collection and analysis. The case study approach has enabled the gathering of information during the study and for that data to guide each next step of the study.

To determine the questions for the questionnaire, the researcher first reviewed literature around the research questions. The study by Estebaranz et al. (1999) also investigated ongoing professional development within a cluster of schools and the researcher found that the Andalusia group questionnaire was useful as a guide for developing a framework to investigate the research questions. The framework formed the main structure for investigating the three research questions throughout this study and included six key aspects for investigation with sub-questions: The questions and sub-questions were linked to the three research questions with overlaps and information gained from one aspect often useful for another. It is important, according to Gall, Borg and Gall (1996) to keep the study manageable and meaningful by concentrating on a few key aspects. The focus for the study is just six key aspects on which data collection and analysis will concentrate to answer the three research questions. 


\section{Six Key Aspects for the Investigation with Sub-questions.}

\section{Description}

Which schools participate and how is/was this decided?

Who comes from these schools?

Where and how often are the meetings held?

How is the professional development financed?

To whom is the cluster accountable?

\section{Administration}

What is the history of the initiative?

What factors enable it to continue?

How and why has it changed from inception?

Why does this model appeal in this region?

Who were/ are the key players and what were /are their aims?

What influences have guided the direction of the model?

What responsibilities do individuals have within the group?

\section{The Content of Professional Development}

What are the focus areas for the last three years?

How were these decided?

What other professional development occurs for the participating schools?

What are the expected outcomes for teaching practice?

What are the perceived outcomes for student learning?

\section{Interpersonal Relationships}

Why do principals choose this style of professional development?

How does the group establish and maintain collegiality?

What enables this approach to increase the likelihood of change in teaching practice? 
5. The Meetings

What usually happens?

Who decides?

What resources are needed?

How is the process monitored or evaluated?

6. How has professional development supported the following:

- teacher leadership

- collegial support

- collaboration

- classroom practice?

\section{Links between the six key aspects of investigation and the three research questions.}

Why are the principals of six rural schools using a cluster model for most of their professional development?

This required a description (first aspect of investigation) of the model and background information about the administration (second aspect of investigation) of the initiative. It also needed an indication of the sort of group that had developed and their style of interpersonal relationships (fourth aspect of investigation).

How is professional development achieved?

Background information was needed about the content of the professional development (third aspect of investigation). It was necessary to know what usually happened at the meetings (fifth aspect of investigation). It was also important to know how the professional development was supporting the principals (sixth aspect of investigation). 
What factors are sustaining the cluster model?

This was to be answered from all six aspects of the investigation.

\section{Procedures and Data Collection}

This pocket of clustered schools appeared to the researcher to have a unique approach to their professional development needs. After unofficially asking the principals if they would be interested in participating in a research project and gaining their verbal approval, the researcher began the steps towards making this happen.

Two institutions were involved with the study. During 2002-2003, while the researcher was an employee, Christchurch College of Education provided some funding for travel and research costs. In April 2002, Christchurch College of Education Ethical Clearance Committee cleared the project for literature search and review and then in May 2003 gave ethical approval for the collection of data such as surveys, interviews and observations that involved investigation into human participants (Appendix A). Approval was on condition that Ethical Approval was gained from Victoria University of Wellington.

The next step was to gain approval from the Research Committee, School of Education Victoria University of Wellington in March 2003 (Appendix B). This was then followed by obtaining ethical approval from Research Ethics Committee, School of Education, Victoria University of Wellington May 2003 (Appendix C).

After gaining ethical approval from both Victoria University of Wellington and Christchurch College of Education, the consent and information letters for participating principals and providers were designed and approved (Appendix D). The Principal Consent to Participate and Information letters were then posted to the six principals

Five of the principals agreed to participate, with the sixth principal declining the interview but indicating willingness to participate in other parts of the study. 
Data were to be collected from six different sources: the key principal interview, the questionnaire, the participant principals’ interviews, historical documents, observations of meetings and an existing provider interview.

1. The key principal interview was designed with questions for six aspects of investigation, (description, administration, content, interpersonal relationships, the meeting and professional development support for teacher leadership, collegial support, collaboration and transfer to classroom practice).

These aspects were the same as those used by Estebranz et al. when investigating the Andalusia model. The interview was taped and responses from this initial interview were analysed and used to guide the development of the questionnaire.

2. Survey questions for the questionnaire were developed (Appendix E) The survey was designed to gather demographic data about individual principals, their career paths, other professional development experiences, and benefits for them personally and for their schools and their vision for the future. Collated responses from participants were used to investigate individual and common responses to the professional development model.

3. Participant principal face-to -face interviews were conducted on site with five of the six participants. Transcripts were taped, transcribed and sent to participants to delete or review. The transcriptions were analysed to gain generalisations. Responses were selected from the transcriptions and grouped under the six research headings. This was done by coding responses with the number of the heading to which it best related.

4. Historical files analysis was limited to past agendas.

Information gleaned was summarised to determine the length of involvement of participants, frequency of meetings, content over years of professional development and how the model has evolved.

5. Observations by the researcher included written anecdotal reports of two meetings 
investigating the process, content of the meetings and an analysis of the interactive patterns of the participants.

6. A semi- structured interview with an existing provider was recorded with field notes by the researcher. The interview was to provide triangulation with data from the questionnaires, interviews and observations.

\section{Data Sources and Analysis}

\section{Key Principal Interview}

Data collection began with a face -to -face interview with one of the key participants in the cluster. This principal was selected because he had been principal of a school in the cluster for the longest time.

Questions for this participant observation interview were developed so that the subject could be investigated, including the principal's attitudes to professional development, relationships with other principals, his personal philosophy of education, historical knowledge of the formation and development of the cluster model. The questions to be asked were emailed to the principal prior to the meeting.

The key principal interview was structured with questions organised under the six main aspects of investigation: description, administration, content, interpersonal relationships, meetings and how the professional development had supported leadership, collegial support, collaboration and classroom practice.

1.1 The first section was to do with a description of the model. It included identification of the schools that participated and who participated from each school. Questions were asked about funding and to whom the cluster was accountable. 
1.2 The second section was about the administration of the model. This included questions about the early beginnings and the factors that have sustained the cluster. Questions were asked about individual and group responsibility.

1.3 The third section was concerned with the content of the professional development. This included questions about the focus for the last three years of the cluster and the perceived outcomes for teachers and students.

1.4 The fourth section was about inter-personal relationships of the participants. Questions were asked about the reasons for the principals’ participation and how the group established collegiality. The style of professional development was described with some suggestions about how and why it has evolved.

1.5 The fifth section was about the meeting procedures. These questions explored how decisions were made and how the process was monitored or evaluated.

1.6 The sixth and last section was concerned with how professional development had supported the following: teacher leadership, collegial support, collaboration, transfer into classroom practice. There was an opportunity at the conclusion for reflection and open discussion with the key principal.

This interview was recorded and transcribed and sent to the principal for correction or comment. There were a small number of typist errors that were corrected. The transcript was then examined by the researcher to identify key facts and perceptions about the function of the cluster. This was used to develop survey questions for the questionnaire for the other participating principals. Consultation with the key principal before proceeding with the study helped to minimize researcher bias. From the outset it helped with empowerment and generated interest in the results of the research by all participating principals.. Bouma (1996) found that through consultation,"errors of fact and of interpretation can be discovered and corrected”. (p.184) 


\section{The Questionnaire}

The questionnaire was developed using information gathered from the key principal interview. The survey aimed to gain the other principals' perspectives and knowledge about the cluster model, allowing for comparisons with the key principal's responses. All respondents were asked the same seventeen open ended questions beginning with demographics. (Appendix E) The remainder of the questions focused on the benefits of participating in the cluster professional development personally and or for their school. Specific examples of how the cluster style of professional development supported development in leadership, collegiality, collaboration and classroom practice were requested.

The questionnaires provided the principals the researcher with background for the participants' interviews, which followed a few weeks later.

The questionnaire was piloted with a group of teachers interested in professional development but not involved in the study, and modified before being mailed to each participating principal. It was also emailed and principals were given a choice of how they responded. All used this option while two mailed a copy as well.

The completed questionnaires were analysed as follows:

1. Demographic information was gathered and tabulated to provide a description of the participating principals.

2. The individual responses were compared to find commonalities and differences.

3. The results were analysed to describe the range of activities during the year (2003).

\section{Participant Principals’ Interviews}

Questions were developed after the survey was completed for a semi-structured interview with each participant principal. The questions were designed to probe some of the issues that had arisen either from the key principal interview or from individual responses in the survey. While this provided a guide for the interviews the questions asked frequently followed the direction of the responses. Not all interviews had been expected to cover the same questions. Sometimes there was a change of emphasis of a question or a similar question was posed in a different way so that the researcher was able to gather different 
information from each interviewee depending on their interests, knowledge and experience. At other times the researcher was able to pursue a line of questioning in order to gain a more in-depth response from the participant as recommended by May (1997).

The follow-up interviews were held at each school during Term 3, 2003.They provided an opportunity to follow up on areas of particular interest to the principals and help the researcher gain a rich understanding of the principal's perspective. The principals had been told that the interviews were going to allow them to expand on their responses to the survey. In some cases questions were asked about future possibilities in relation to past experiences that had been recorded in the survey. The aim of each semi-structured interview was to generate answers to the research questions through using the framework of the six key aspects of investigation.

The interviews were recorded and transcribed. The researcher selected statements from each participant principal interview that related to the six key aspects of investigation. These were identified and coded 1 to 6 to match the six key aspects. The original participant transcriptions were given to a colleague who was asked to code them in the same way to check reliability. She matched sixty-one of the sixty three identified statements to the agreed code Some rearrangements were made to the placement of the statements that were not in agreement with the researcher's decisions. (Appendix F)

The selected statements were then expanded and combined with the results from the survey

\section{Historical Files Examination.}

Past agendas held by the lead principal for the year were examined to gain an understanding of the scope of the cluster's activities and how the cluster model had evolved. The agendas included a mixture of paper copies and more recently emailed versions of agendas that had been circulated to the participants. Generally, the agends revealed that the focus of the cluster had moved from afternoon meetings for planning sports and cultural events to day meetings that allowed time for more personal interactions, discussions, problem solving and development of projects. 


\section{Observations of Meetings.}

These observations allowed the researcher to cross check both the questionnaire and interview results and to observe and record interpersonal relationships within the meeting process.

The first observation of a professional development meeting was on August 1, 2003 in one of the participating schools. Field notes were taken and data gathered specifically on the format of the meeting and the group dynamics. The researcher took anecdotal notes and records of participation particularly noting the speaking order of the principals. Schmuck and Runkel (1982 ) discussed the way that groups worked together and likened a group to a 'living system' that was more than a collection of individuals. Their research identified key factors in describing groups as well as outlining the stages of development of groups. The researcher recorded the participation of the principals in the meeting as a way of testing how the group matched Schmuck and Runkel’s 'happenings within groups'. ( p.744).

The second observation was planned for October 2003 but was cancelled by the principals because of bad weather and so the researcher attended the next meeting in February 2004. (Appendix G) This meeting was held in a different venue, with a different focus and with only four of the participating principals, one of whom was no longer principal of a school in the cluster but who was attending for personal interest. The original intention had been to continue observations at the second meeting of the participation levels of the six principals but this now became unavoidably impossible. Observation notes were taken of the second meeting and significant points for the study were recorded .

\section{External Provider Interview.}

An interview was held with a professional development provider for the six schools involved in the case study. The aim was to gain an outsider's provider's perception of the model. A semi-structured interview took place towards the end of the study. Field notes were taken during this interview. (Appendix H) This provided triangulation with the permanent products such as written and audio taped data from the principals' interviews, the survey and meeting observations. 


\section{Reliability and Validity}

Meeting notes and audiotapes of all interviews and observations were kept for checking reliability. Bouma, (1996) says that a valuable asset of recorded or written materials is that you can go back over the material to check reliability. (p.84) Reliability refers to problems in the accuracy of the measuring device. Reliability can be checked by asking if the same measuring device would get the same results for other researchers when they measured the same event. The researcher checked for reliability by comparing the outcomes for some of the sorting and coding results for the survey and interviews with another colleague's responses to the same task. All participants were given the opportunity to check transcripts for accuracy and invited to correct or amend.

The problem of validity is considered by Bouma to be "most acute in the construction of questionnaires or interview schedules to 'measure' a person's attitudes or beliefs or values.” (p.83). In addition to being careful in the construction of the questionnaires and interview schedules and the interpretation of observations, the researcher asked friends and other professionals to comment on the measures. Several versions of the questionnaire were constructed before a final version was used. The researcher was also guided in the construction of the questionnaire for the survey, by the version already tested for validity by Estebaranz et al.

\section{Summary}

The major strength of the methodology was that it involved a variety of methods for gathering data. At the outset it was impossible to predict what was going to be the most useful in providing findings, relevant for the study. This was because it was difficult to gauge how responsive the principals would be to an outsider investigating an initiative that represented their personal vision. It became important to keep reflecting on the process of gathering qualitative data to ensure that the research was proceeding to the original plan. 
This chapter has described the tools used for gathering data. It has outlined the degree of isolation experienced by the principals and reported the steps taken by the researcher to capture their responses. In chapter four the results of the data collection will be presented. 


\section{CHAPTER FOUR}

\section{Results}

This chapter describes the results from the interviews, the survey and the historical document search. The introduction will begin with a discussion about the changes that occurred in the research process. It will then profile the principals and their locations. The results of the key principal interview, the survey, the participant principal interviews, the observations of meetings and the provider interview will be reported under the six aspects of investigation as outlined in chapter three. They are: description, administration, content, interpersonal relationships, the meeting and professional development and practice.

When it was considered relevant the principal making the statement is identified according to the letters used in the profiles. Selected responses from the questionnaires for the survey are in the appendices, with the coded responses under the six aspects of investigation and their sub-questions (Appendix F). Finally the key findings will be drawn from this analysis to report on the research questions:

Why are the principals of six rural schools choosing to cluster for most of their professional development?

How is professional development being achieved?

What are the factors sustaining the cluster model?

\section{Introduction}

There were three main changes from the original methodology for gathering data.

Firstly, the search through historical data proved difficult. The participants were happy to share past agendas with the researcher, and continue to mail agendas for current meetings, but past files were shared amongst the previous chairpersons and not collected in any one place. During the last three years, all notes and minutes have been held on computer and for reasons of convenience, there has been a conscious effort to use computers and leave a very small paper trail. Some participants know the history of the cluster, while others referred the researcher to a principal, who is considered to be the historical spokesperson. Much of 
the history of the cluster model has had to be gleaned from informal conversations and discussions from both within the cluster, and other educational settings, such as the School of Professional Development, Christchurch College of Education.

Secondly, one principal who had just been appointed when the study commenced originally felt unable to participate because of time constraints and lack of knowledge about the cluster. During the year, the principal did become involved with the study and only declined the interview. This was unfortunate, because a new principal's perspective would have been useful to the study. Opportunities for informal discussion and comment did eventuate.

The third change was the rescheduling by the principals of the cluster meeting, which was to be the second observation by the researcher, from October 2003 to the beginning of 2004. By this date, three of the original six principals had changed, so the focus on group process was limited to the original observation. The second meeting did allow for observation of new members involvement with the cluster.

\section{Profiles of the principals in the cluster in 2003.}

The following profiles have been developed from information provided in the interviews and questionnaires.

Principal E

Principal E has been involved with the cluster for a longer time than any of the other principals. For this reason he was selected for the initial key principal interview. E has an interest in mentoring approaches. He has had leadership responsibilities and opportunities for providing feedback to Ministry of Education initiatives. E is a teaching principal but unlike the other principals, E does not live in his school's community. He lives in a small town about thirty kilometers from the school. 


\section{Principal S}

S was acting principal, while the principal of the school was on maternity leave. He had had some previous involvement with the cluster when he attended professional development events to which teaching staff was invited. The interview was held on a Friday evening in the schoolhouse.

\section{Principal C}

Ten years previous, after completing his teacher training, $\mathrm{C}$ had been employed at the school for two years. At that time the school had two teachers and a teaching principal.

When C returned as principal, the school was sole charge. This school is considered to be the second most remote school in New Zealand. It is located about two hours' drive from the main highway. Many children travel to school using a combination of transport that can include boat, farm bike, tractor and the school bus. The interview was held during the school holidays in the schoolhouse.

\section{Principal P}

$\mathrm{P}$ is an experienced principal who is the current convener of the cluster. $\mathrm{P}$ has been exploring community-learning options, centred on the school. The parents and students who attend this school, live isolated from each other and from the school. Several students come to school by boat from a nearby island. This sole charge school was considered to be the third most remote school in New Zealand. It was located about one and a half hours' drive from the main highway. The interview was held in the schoolhouse on a Friday evening after the last students had been collected by boat.

\section{Principal M}

M had become principal earlier in the year but had previously attended the cluster as deputy principal for a number of years. M's school was the biggest school in the cluster. It was an area school with students aged from five to eighteen years. The school was situated 
on a main road between two cities. It was not as isolated as some of the other schools in the cluster but $\mathrm{M}$ described similar reasons to the other principals for wanting to participate in the cluster. The interview was held in the school library during school time.

Principal K

This principal who had been teaching longer than any of the others had been principal of the school for just one year. $\mathrm{K}$ was principal of a school that had been the focal point for the farming community since it first opened in 1867. It was situated on a highway between two main centers. Although unable to participate in the interview because of time and work commitments $\mathrm{K}$ chose to complete the questionnaire for the survey and participate in the observations

\section{Results Reported Under Six Aspects of Investigation}

The results from the interviews, the survey and observations are reported under the six aspects of the investigation. Relevant information is reported under each of the subquestions.

\section{Description}

Which school principals participate and how was this decided?

There are six schools in the cluster and the biggest factor that determines which school principals participate is the geography and the roads. Some other schools on the periphery of the cluster region were already associated with other main centers because of alternative road or boat access. They had already chosen to travel in a different direction for shopping or business facilities so connected with other schools in other locations.

Who comes from these schools? 
Currently only principals participate in the cluster because they feel they have specific needs that can be met through this model of professional development. K said that she was thrilled to be part of this group in her first term as a principal.

Several principals commented that they would like to include all staff including support staff and board of trustee members at some time in the future. Funding is one of the barriers to this happening and the other is the difficulty in finding relieving teachers in these locations. One principal suggested that a few more teacher only days would provide a satisfactory solution to both the funding and relieving teacher issue for remote schools.

Where and how often are the meetings held?

The cluster meetings are held at least twice a term and rotate around the schools. Most meetings begin at ten o'clock to allow principals time to travel from their schools. The meeting observed by the researcher was held at a school that required one principal to drive for two and a half hours and another for two hours to attend the meeting. Meetings end at about five o'clock. The cluster found that afternoon meetings were not long enough so a whole day is now being set aside. This is a significant change as E feels that "teaching principals don't like to be away from their classrooms and parents don't like to see them out of the school yet, they deserve as much professional development as any other staff member."

How is the professional development financed?

All principals are involved with the cluster with the support of the board of trustees from each of their schools. Travel is sometimes funded from the school budget but usually by the principals personally. Principals attend the meetings during their principal release time so relieving teachers are not required. Some external funding has been accessed through the Ministry of Education and this has enabled the cluster to initiate new projects. Two years ago the cluster had two projects which as E says," Gave us an excuse to meet”. One was to do with sports events and the other was to do with leadership and appraisal. Both of these projects had some external funding. This year (2003) as a result of discussions within the cluster there is a new project to do with researching transition from preschool into primary schools and from primary schools to Secondary schools for students in the cluster. External funding is paying for a person to gather information and report back to the cluster on findings and recommendations. The survey showed that funding was not a high issue for 
the principals. One principal felt that the cluster was "probably not" funded sufficiently while two indicated that they were "not sure" and the three remaining principals said," yes,” “used to be,” and “only just.”

To whom is the cluster accountable?

The cluster principals are accountable to each other and to their individual board of trustees. All principals described benefits for themselves personally and professionally as well as for their schools and communities from participation in the cluster.

\section{Summary}

In 2003, principals from the six schools in the cluster met in each of their schools, for a day, at least twice a term. The schools have similar locations separated from each other by water or mountain ranges but because of roading patterns, able to access each other relatively easily even though some drive for as long as two and a half hours. Isolation is part of the reason why they meet but also influences who meets, and which schools .participate.

Attendance has always been voluntary and during the year, 2003 most principals were actively involved in various parts of the professional development programme. The cluster is dependent on the principals at the time for the way that it functions. It is a flexible organisation continuing to evolve yet able to maintain key characteristics.

Participation has varied from year to year but since the cluster has become focused on projects that have generated funding it has become a stronger group with a sense of purpose and vision.

Some principals said that at first they felt that they did not need such a group but it did not take long for the isolation “to kick in”. Another principal immediately found the cluster when he was told of the mentoring focus because he knew that that was the style of professional development that he needed. 


\section{Administration}

What is the history of the initiative?

The association was in place when principal E arrived at his school ten years previously. It was loosely associated with combined and interschool sports and cultural events. There was a meeting once or twice a year always orientated around an event and next year's calendar. Over time the principals involved started developing an idea that included time for a professional "chat". E was aware that principals can feel isolated because of location and that it is hard and not always appropriate to share some of the issues with a spouse. The principals started with issues of common interest and included opportunities for professional discussion. $\mathrm{M}$ has been involved with the cluster for about nine years and said originally it was a group that met together for a few drinks and discussions about sports events. The model changed drastically when the mentoring programme ran because there was a formal side as well as a social side to the meetings. When the principal mentor programme was in place the meetings were structured around readings to do with mentoring. Once that finished the programme was organized to satisfy the needs of the group. $\mathrm{C}$ felt that the readings and the agenda became more personalized and professional. $\mathrm{S}$ felt that the depth of the discussions and the purpose of the meetings had grown a lot recently. He felt that the participating principals have taken a step in a direction and then thought of how they could move even further. S said the latest thought was to plan joint professional development for all staff. He can see benefits, as it will build on the collegial support already well established. It will benefit teaching staff including support staff that faces the same issues of isolation from other professional people.

\section{What factors enable it to continue?}

$\mathrm{P}$ has found it essential to have regular face-to-face contact with someone like a mentor or support person from a similar school environment. One of the strengths of the cluster at the moment is that many of the principals have been interacting with each other for over two years.

S considers the social side of the meetings to be very important as he enjoys opportunities for informal conversations and social interaction. Although the schools are different sizes there are a lot of similarities so same issues arise. S says he doesn't feel alone because he is 
part of a group of like- minded people and treated equally. The group is not too big so that the participants know each other well. "Some other principal groups are full of the big boys who hold the limelight."

There are other factors that sustain the cluster. C felt that the model had been well established using a mentoring leadership style with a framework set up so that good things could happen. There are contributions from the group for the group. Communication continues between cluster meetings and not just at a professional level but also at a personal level.

When the principals were asked to name the main strengths of the model they listed collegiality, collaboration, support, enjoyment, equality, trust, sharing, local collegial support and self-direction. The language used displays a high level of understanding of best practice for the provision of professional support in education.

How and why has it changed from inception?

E said that the principals of the six schools in the region frequently changed and the cluster felt the need to "hold hands" not just for sports events but also for professional aspects of the job. The people who choose to be principals in isolated schools have unique characteristics so when you place them together those characteristics form the special character of the group. C suggested that the needs of the participants are similar as a result of the sameness of the communities and schools that they serve. He felt that the uniqueness comes not just from the communities but also from the principals who choose to work in remote rural schools.

Why does this model appeal in this region?

The model appeals in this region because it allows principals to share same concerns and new knowledge with other principals in a safe environment. (Table 4.1) The cluster is structured in a way that suits them allowing for free speech. This was listed by four of the six principals as appealing. $\mathrm{P}$ believes that there has been a tradition in teaching that stretches back through years of teaching that teachers don't share what goes on in the classroom He considers that regardless of the size of the school it can still be like that. This can happen with principals too. P says, "When you are principal of a small school it is even 
more important that you can share with someone who understands your situation.” When P was having a tough time at his school he says he was able to put the problem into perspective when he heard what was happening in other similar schools. The sharing was a form of reflection and helped him to confront the problem.

S thinks that many professional development providers tended to think their particular area of expertise was all that mattered and did not take into account the whole job. He believed that there was no one better to ask about issues to do with being principal of a rural school than somebody who was in a rural school. $\mathrm{S}$ did attend courses facilitated by external providers and while he acknowledged that this year he was preoccupied with his new role of principal he has frequently thought" There is nothing new for me here"

P felt that the model was unique to the region but some of the ways that things were done in this model could transfer. He had been involved with a cluster when principal in another region but that model suffered because it was hierarchical with some principals from bigger schools dominating the meetings.

C said that during a pre-principal induction course he looked at what was operating in the area and found that there was a trial mentoring scheme available. After more enquiries he found that it was built into a cluster professional development model. He went to the next meeting and has continued to be involved.

P said that prior to coming to the school he had no knowledge of the cluster despite working previously in another school in the region. For the first year he did not see the relevance of the meetings so he did not attend. During his second year as principal he realized he needed to get out and mix with other principals.

$\mathrm{M}$ found it hard to find a group that was supportive with relevant information specifically for the role of principal. As a new principal there were invitations to join several different groups. Although “loaded up with professional development" $\mathrm{M}$ chose to continue involvement with the cluster because of their collegiality and because the focus was on issues common to the school community. 


\section{Table 4.1: Appealing features of the cluster indicated by principals in the questionnaire.}

Relationships/support

Cooperation of cluster

Structure of cluster

Other

\section{No. principals}

4

3

4

2

Who were/are the key players and what were/are their aims?

The researcher had identified $\mathrm{E}$ as a key person in the cluster as he had been involved from the cluster's early beginnings and had remained principal of the same school when others had moved in and out of schools in the cluster. E considered what would happen if he moved from the cluster and if it would continue. He thought that it probably would now. He commented, "Every time someone walks in and out of a room the dynamics change. We have had changes of principals and it hasn't fallen over. Now that it is up and running there is energy in the cluster."

The researcher asked $\mathrm{E}$ if there had been situations when the cluster had been at risk.

E replied, "Yes I once thought an issue was going to be powerful enough to blow the group apart but both people took a step back. Often other people in the group help sort out issues between people. Negotiation and diplomacy are skills that are needed and sometimes, the short abrupt approach works."

What influences have guided the direction of the model?

$\mathrm{P}$ said that ideas have come from the cluster and there has been some funding to keep the momentum going. The Ministry funded projects have been a carrot to get initiatives from the principals started and there have been enough now so that the cluster has been able to grow building on what went before.

C suggested that email had made a significant difference for him It was more useful than an answer phone or walkable phone because it can be read or answered at your choice of time and place. $\mathrm{C}$ said that being able to send emails to his home was another advantage as well as having a paper copy. Email has been useful for teaching principals who have a school 
secretary for limited times each week. It not only enables a paper copy but also provides flexibility as the message can be read or replied to at a convenient time.

Consistency is achieved too, as everyone receives or can add to the same message. E said that a regular communication system was very important for the convener who not only has the responsibility to cc-ordinate the meetings including providing the agenda but also preparing the other participants for each meeting. This can be reminders or starter questions about the professional readings or issues that have arisen that are to be the focus for the meeting. The secretary also emails the minutes to all the cluster principals so that they have a record of what actually took place. This is one of the factors that kept the principals informed so that the cluster continues.

Computers are reliant on power and the region often suffered from power cuts or both telephone and power lines down. Lightning strikes have put computers out of action on several occasions. Technology works well when it is working. Delays in getting computers repaired often forces principal C back into isolation.

What responsibilities do individuals have within the group?

The biggest responsibility that each participant has is to remain in communication and that has been achieved very effectively over the last few years with email. E thinks email has helped the cluster considerably as it has stopped principals playing “telephone tag”.

In $2003 \mathrm{P}$ was the chairperson/convener who took a leadership role and was responsible for keeping participants informed and maintaining momentum. The principals rotate the convener of the cluster role. They always have even when it was sports orientated. Basically it was for issues of fairness but also to offer opportunities of leadership. Although principal E did take a lead role for two years he now sees himself as a contributor rather than the leader, He did not consider there was a problem. He felt that when people see others doing the job they are happy to say, "OK I'll do that"

\section{Summary}

The reasons for meeting together have changed and continue to change. Despite the changes of participants, the cluster has strengthened its focus from sports organisation and 
information sharing to initiating research. The model began with meetings but gained direction and momentum by participating in a mentoring contract some years ago. This not only strengthened the cluster by giving it a purpose for more regular meetings, but also provided a learning environment that suited the philosophy of the participants at the time. This is significant because the participants have indicated that inter-personal relationships are now the cluster's greatest strength.

\section{Content of Professional Development}

What were the focus areas for the last three years?

During the last three years there has been a focus on leadership, school culture, appraisal and the transition project. Other topics had been shared with the cluster as the participants brought new learning from other courses and readings from various sources. $\mathrm{C}$ said that the readings come from a variety of sources such as gazettes, educational journals, magazines, newspapers, course handouts or publications from the principals ' federation. "When it is your turn you select what interests you and mail copies out to the other principals. “

E described some interesting readings that the cluster had on school culture that were shared the previous year (2002) In some schools these were shared with the staff but as a cluster of principals they decided that before their next meeting each participant was to go and work in another school in the cluster and report back on their findings of that school's culture. E said "That was neat and about three months of discussion revolved around school culture after that. It was hard for sole charge schools though.”

\section{How were these decided?}

Decisions about what is to be the focus come from group discussions. The transition project is an example of how this happened. S said that during the time called 'Off the Top' several principals had questioned how their children were being prepared for entry to primary school. Most of the preschool children in the region do not attend preschool facilities so the move into school can be a big step for the children, their parents and teachers. The children do come with skills that are not always recognized by existing pre-entry assessments The 
group formulated a budget and a research programme to investigate transition provision both from preschool to school and from primary school to secondary schools within the cluster region. In 2003 a researcher was funded to gather the data and report to the cluster at each meeting. This has become a major part of each agenda. The transition project has shown what can happen when an experienced person is funded to coordinate a project too big for busy principals but initiated and managed by them.

C said that the readings are presented by whoever has taken responsibility for them by starting a discussion around a focus. "Everybody gets a slightly different angle from a reading. Sometimes you might start off thinking one thing then once it has been challenged you change around. Sometimes the thinking will be theoretical and you will try and put your school and community in the picture."

C believed that the professional development has not become stale or inward looking. " It could but it hasn't because the individuals within the group are diligent about their own personal development. When we had readings from a 'top down' approach they weren't always relevant. The way it is now they always are and are attractive because a friend has found them useful and is handing them on. They are a living example rather than a piece of paper.”

What other professional development occurs for the participating schools?

From the survey it was found that the principals in the cluster in 2003 were participating in a range of other professional development from a variety of outside providers. (Table 4.2) Not everyone in the cluster attended professional development provided by the college of education or other providers. Whoever went had a responsibility to upskill the other cluster principals. At present two principals are involved with a Ministry of Education contract and they will support the others when it is finished. 
Table 4.2: Involvement in other professional development.

\section{no. principals}

Literacy leadership

3

Personal Research Transition Project 3

Visual Art workshops $\quad 2$

Principal's Induction $\quad 2$

First Aid 1

$\begin{array}{ll}\text { Mentoring } & 1\end{array}$

Principals’ Association 1

ICT PD 1

NZEI MST training $\quad 1$

NZPF executive 1

REAP 1

MOE School Planning\& Reporting 1

S suggested that the principal knew best what was needed for his/her school but often does not always know how to make it happen. He would like relief from external compliance with professional development in his school. S said, "I feel that it would be good occasionally to have year off with no professional development or staff meetings with time and energy to try new ideas and consolidate understandings of teaching and learning. I would have some goals and work towards them and provide some form of accountability for what I was doing."

The principals listed activities other than meetings initiated by the cluster:

Sports events, swimming, athletics, cross-country, gymnastics, winter sports day, orienteering, aero-gym,

Cultural events, speech competitions, art displays,

Cluster project meetings,

Mentoring meetings,

Year 7/8 transition career days,

Pre-meeting preparation of readings,

Social functions involving spouses. 
What are the expected outcomes for teaching practice?

When $\mathrm{C}$ first began attending the cluster meetings, they were mostly concerned with the mentoring programme and sports administration. Since then, a project has been suggested each year, that was of mutual interest and benefit to the schools and an application for external funding has been successful. The current project is researching transition provision. The transition project is expected to have benefits for all schools and communities in the region. One of the biggest outcomes for $\mathrm{S}$ is that the teachers and parents of students at the school will know that their students are being well prepared for college. The school does not work closely with any of the colleges so the school community will be very interested to learn from the research.

\section{What are the expected outcomes for student learning?}

The transition project is still in progress (2003) and includes research and a programme for year 7 and 8 students. C says that already the research has raised awareness within the schools and boards of trustees, of what is good practice. It has already shown, that some of the activities are not as good as were thought. It has also shown, how stakeholders in preschool and secondary schools can influence outcomes for students. School communities were surprised at some of the negative experiences of their year 9 students. C suggested, that next year (2004) when the data gathering stage had been completed there would be more community action and policy development.

\section{Summary}

Professional development for these principals is now a mixture of regular focused meetings, email, facsimile and telephone contacts. There are also informal meetings for combined school events, such as sports, pet days, camps, and special shows such as those for drama, gymnastics or music. The principals are currently involved with other outside professional development options and larger regional principal study days, but the focus for this study has been the system set up by the principals for their own professional development. This includes at least two meetings each term that are specifically identified for professional development and are attended by principals, and occasionally for special topics, by their teachers. The principals have designed their own package for professional development, which is needs based. Their needs are sometimes for their role as principal 
and at other times for their role as teacher. This dual role is another unifying factor and part of the uniqueness of the cluster makeup. For these reasons, the principals in the cluster want control of the content, time frame, location and delivery style of their professional development.

\section{Interpersonal Relationships}

Why do principals choose this style of professional development?

E felt that one reason that the cluster continues and principals choose this style of professional development is the desire that participants have to be included and for them to be able to maintain what they have and consider being worthwhile. He said, " It is not an adrenalin rush but it satisfies a need to try your ideas out against other professionalspeople you can trust. You can't do that in your environment and you can't do that with your board (of trustees. You can't take risks or have the missing bits added or generate more discussion with them. There's always a buzz from passing on what you know to other people and that's what keeps people coming."

E considered that the geography of the region has influenced the way the cluster has evolved and now functions. Because of the remote geography, an affinity has been developed among the principals as they all understand the characteristics of the remote communities in which their schools are located. However E believes that relationships are a more important factor than geography in determining the uniqueness of the cluster but concedes that the former may have come as a result of the latter. When principals are in a supportive network such as the cluster they tend to contact one another before trying any other service. These are the people with whom they have established a relationship, the people they have come to respect and the people whose opinion they value and trust.

How does the group establish and maintain collegiality?

When a new principal joins the cluster it is not difficult to come into the group or for the group to include a new person. A new principal usually takes a minor role until they feel confident to contribute. The group feels connected to the reasons for the meetings and new 
principals are usually quick to appreciate and support the cluster. C said it was easy for him to become committed when he was anew principal as he was keen to meet other professionals because it did not take him long to feel lonely. C said at first not too much was expected from him but it was assumed that he would share his concerns and questions from the outset. He said he was listened to from the first meeting and felt part of the group straight away.

The cluster continues to establish and maintain collegiality because it fulfills a social function but it was more than a social get together. C said that the group was made up of professional people who met in school time. They are paid to be at the meeting and to produce something worthwhile that will benefit their schools. One of their needs was social contact with other professionals and this happens. C said that, they got a lot more done when they were having fun too.

Collegiality, was becoming increasingly important says $\mathrm{P}$ yet it was hard to achieve with the distances and the time it takes to get to a meeting. P saw the need to get together regularly, even just socially, as of prime importance. Email has helped the group to keep in contact in between meetings but $\mathrm{P}$ felt the need for face-to-face contact. He saw the need for contact as being a universal need and not confined to isolated school principals.

S considered that the cluster meetings were more than a social outing but the social part of the meetings was very important because it was a chance for interacting with people who had relevant knowledge. He looked forward to the cluster meetings because there were people there with whom he felt comfortable while learning new skills. S rarely requested information from other sources as he said," They are faceless and I don't know what they know. I don't know what I can actually ask without doing lots of scene setting”.

Professional development for this principal would always include an "afterwards time”, a time for socializing and talking about the issues that are in front of principals or teachers as a result of new learning. 
What enables this approach to increase the likelihood of change in teaching practice?

From the survey results to the question: what are the benefits for you personally and professionally from participating in this cluster, five of the six principals responded with "sharing of problems with experienced principals". (Table 4.3)

Four of the six principals saw that from their participation in the cluster they were benefiting with personal and professional growth. Three participants have listed friendship as one of the benefits. All of the responses are associated with issues of collegiality and being able to interact with other professionals in a collaborative way making social and professional connections.

\section{Table 4.3: Indications from principals of personal and professional benefits}

\section{Benefits}

Sharing of problems with experienced principals

Personal and professional growth and support

Friendship

Advice about principal-ship

Discussion of readings

Peer support from those interested in me

Sharing resources

Respect as a principal

An important lifeline

Face to face support and contact

An opportunity to give back

Safety to explore, critique, reflect.

\section{no. principals}

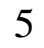

4

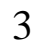

2

2

1

1

1

1

The survey responses, (Table 4.3) reinforced the value of feeling supported and being able to support feelings of belonging, of being in a non-judgmental environment and being in control of the professional development. One principal said, "We set the focus, we seek the resources, we meet the real needs at the time we feel it is needed." 
The flexibility with the focus and the time frame was confirmed by another principal who said, "Sometimes it is like experimenting to see where the journey will take us."

Another principal valued the readings that guided the discussions while another liked being face to face with others discussing content that was not overly theoretical book or Internet based.

These principals have found ways to get their needs met as people as well as, as principals. . C says, "We look at each other as people rather than as principals."

\section{Summary}

The principals have shown in the survey that they consider the strength of the model to be the provision of opportunities for shared decision making, leadership, collegiality, trust, equality, peer support and professional dialogue in a non threatening environment.

This is time out of their schools allowing them an opportunity to reflect and engage in meaningful discussions with their peers, which they are unable to achieve in their own schools

\section{The Meetings}

What usually happens?

Each meeting had an agenda that included ongoing planning and management of sports and cultural events, reports from principals with specific responsibilities or feedback tasks and forward planning of dates and venues for meetings

According to $\mathrm{C}$ there was always a caring time with some chit -chat before getting into business. The cluster occasionally invited visitors and staff from schools to join the meetings but they liked to build on the positive way that the group interacted by making sure there was sufficient time invested into their group dynamics at the outset. 
Although the current transition project was exciting and the principals and their communities were interested in the results the most important part of the cluster meetings was considered to be the time called "Off the Top" This was a designated time for unloading and collaborative problem solving by the participants. In the survey five listed sharing of problems with experienced principals as the biggest benefit for them personally and professionally while four listed personal and professional growth and support. (Table 4) One principal said during the interview that he worked in a vacuum for four weeks and this catch up time enabled him to continue working in isolation. Another participant felt that being able to support another strengthened his understanding of issues and helped him to get things in perspective for himself.

C felt that "Off the top" was the most important time for him and enabled him to keep working in such an isolated setting. "This catch up time is when friends can help each other out. It is more important to me than any funding or project. You work for four weeks in a vacuum and then go to a meeting where you hear about the success and failure of others and you feel part of a supported group "

P said that some issues are too big and 'in you face' to manage when you are in an isolated environment so it was good to get them discussed and 'off your chest'.P felt that the cluster gave him the opportunity to confront situations and to put them in perspective. He had been encouraged to reflect on issues and to observe how others handled them. For P this was an example of personal professional growth.

Part of each meeting was spent responding to articles from journals and other academic reading, which had been circulated prior to the meeting. This activity has provided the group with outside knowledge and opportunities for professional dialogue. It was felt that this was one way to prevent the discussions from becoming too inward looking and stale. In the interview one principal said that the readings were 'living examples' rather than pieces of paper because a friend was handing them on rather than down. When the readings came from a "top down” approach he felt that they were not always relevant. 
Who decides?

There was not really a hierarchy in the traditional sense such as one based on qualifications, biggest school, age, years as principal, decile ranking of the school, or the latest Educational Review Office Report. If there was a hierarchy it was based on who had been in the cluster the longest.

During the first non-participant observation of a meeting by the researcher a tally was recorded of the number of times principals contributed to the discussion during four twenty minute periods. (See Table 4.4) This provided an indication of what happened at the meeting and who contributed.

\section{Table 4.4: Tally of contributions to discussion by principals.}

\section{1:00-11:20 11:25-11:45 11:50-12:10 12:15-12:35 Total}

$\mathrm{D}$

K

S

C

$\mathrm{P}$

E
12

4

4

8

8

13
8

3

10

7

13

14
4

0

1

3

6

3
0

24

10

3

10

25

11

29

36

13
43

D gave a report on his progress with the transition project and left the meeting at 12.10pm. From Table 4.4 it can be seen that his responses (24) were recorded from the first three 20 minute observations. From the results for the four periods it can be seen that E made the 
most contributions (43) and $\mathrm{K}$ the newest participant the smallest. Each twenty-minute period shows different principal's contributing but $\mathrm{E}$ is the biggest contributor for three of the four observed periods. $\mathrm{E}$ has been in the cluster for the longest time, he has been a principal for more years, he has been teaching the longest except for $\mathrm{K}$ and has attended all of the meetings so far in the year. $\mathrm{P}$ was the next biggest contributor (36) and his teaching and years as a principal are the next greatest. $\mathrm{C}$ and $\mathrm{S}$ have similar levels of experience and made about the same total contributions. $\mathrm{K}$ who was a new principal and newest to the cluster made the least number of contributions (10) during this observation. She was the only female because $\mathrm{M}$ was unable to attend this meeting. $\mathrm{M}$ who had been the only female involved with the cluster for a number of years believed that gender made no difference to the way the cluster worked. She said that there were different personalities within the group and that was more relevant than gender. They enjoyed social interactions but met to share professional information.

For each meeting, a principal found readings that were of interest or relevant to share with the cluster. When it was S's turn he found readings to do with a staff issue that he was managing at the time. While he was searching for it he found other readings so the exercise was considered very useful. The readings were sent out prior to the meeting to allow for pre-reading. Discussions about issues from the readings were led by the principal with that responsibility and were often lively with different points of view welcomed. E said the group did not have a formal structure for discussion but tended to allow an idea "to float" and then the group would talk it over until they gained consensus. There was a lot of goodwill in the group and an understanding that what might work for one school may not work in another. Outcomes from the discussions could vary from action to inaction. Summaries of the discussions were usually emailed to the principals after meetings.

\section{What resources are needed?}

The principals do look to outside experts when they want to learn more about curriculum but look to each other for guidance and support to do with their role as principals. New principals usually use the principals' induction programme provided by other providers. (See Table 4.2 Other Professional Development Involvement) 
How is the process monitored or evaluated?

Attending the meetings is a high priority for all of the participants. From the survey it was found that five of the six principals attended seven of the seven meetings by term 32003 . $\mathrm{M}$ had attended two of the seven meetings and had indicated to the group that her absence was because she had been unable to find a relieving teacher for the teaching component of her new principal role at the Area school.

If principals come regularly E sees this as part of the monitoring and evaluative process. E considered that the model was working if people turned up. Principals have to satisfy their boards of trustees that the travel cost and time away from the school is justified so there has to be some benefits apparent to the schools. Adult learning is no different from childhood learning. Being confident in presenting new information and knowledge to the group is a form of evaluation. There are opportunities within the democratic process for principals to be both presenters and recipients of new knowledge. According to $\mathrm{E}$ the way that principals participate strengthens their own learning and commitment to the group.

\section{Observations of Meetings}

During the first observation of the meeting the researcher used six key characteristics of group process from Schmuck and Runkel (1982) to focus on the way the group interacted. Using these headings helped the researcher organize the observation findings to explore the extent to which the meetings were collaborative, providing for the exchange of new ideas or skills and responsive to the participants needs as adult learners.

\section{The Group.}

According to Schmuck and Runkel (1982), “A group that gets things done is more than a mere collection of individuals.” (p. 743) They identified three features of a group that acts with purpose to get things done.

The first feature was interdependence. This cluster of principals was a group with designated roles for one year. Within the group there was an expectation that all would 
have input and make contributions regardless of the variation in the size of the schools, their age or teaching experience.

The second feature was having a shared purpose. This cluster has many reasons for meeting with the transition project giving it an additional powerful focus this year (2003).

The third feature of the group was communication. By far the most significant opportunity for communication was within the meeting times when all principals indicated that they felt free to communicate and express themselves. Meeting face to face on a monthly basis was considered the main means of sharing information and strengthening relationships with other professionals. Technology has also been used enthusiastically to aid interactive communication between meetings. With all participants having access to the same information they were enabled to participate with same knowledge. Communication was considered beneficial for the participants’ personal well being as well as for their school communities. The principals expressed frustrations with computer maintenance and repairs. When the computer was working, searching the Internet, using email for daily communication, sharing readings and ongoing discussion became part of the daily routine. Computers generally, were seen as unreliable resources compared with the telephone or fax machine so the computer was just one of the tools that enabled contact with each other and the outside world. Because of the geographic locations of the schools there was a lack of available expertise to sort out computer problems or to provide ongoing training. When repairs are required a school may not have a computer available for a number of weeks.

\section{Influence}

The members of the cluster do influence one another. There is a sense of camaraderie when they meet. They show they are pleased to be together. There were numerous offers to exchange resources and information and these offers were not all from the most experienced principal to the least. There seemed to be a good display of interaction between the participants, except for K who spoke least (new principal) and the only woman present on the first observation day. During the second observation, $\mathrm{K}$ acted as chairperson and was confident and comfortable with that role. 


\section{Roles and Expectations}

The roles are quite clearly defined and are for one year. Movement to a role of responsibility is by choice but there is an expectation that if you have not taken a particular role then you will take your turn some time.

During the day of the first observation control moved around from one to another. At times E was the most frequent speaker when his opinion was sought but there were opportunities for all to contribute to the decisions.

\section{Cooperation}

During the first meeting there was evidence of a high level of cooperation among the principals. The organization and management of sports events required all principals in the cluster to share the planning and the workload. Tasks to do with transport and the programme were equally shared amongst the principals. A camp to be held at a future date involved one school visiting several cluster schools with students being billeted by two other schools. All of the principals displayed willingness at the meeting to cooperate in order for these events to happen.

During the second meeting the tasks from the agenda were spread equally between the four principals attending as it was expected that the new principals would need time before they could be expected to take part.

\section{Problem solving}

During the first meeting this approach was evident in two events. When D was giving his report it had reached a point where he needed clarification from the group. He asked, “ How do you want me to do this?” At another stage in the meeting when time was running out the chairperson asked the group,” What do we want to do?”

\section{Stages of Development}

The group has evolved from meeting to plan for sports events to a Ministry of Education funded mentoring programme then to a group that is based on these principles but no longer wants or needs the direction and monitoring of such a project. It wants 'to do it their way.' 
Summary

From the observations, survey and interviews, it was found that regular time spent meeting with a small cluster of principals is highly valued by all participants. Attending the meetings is a high priority for these busy principals throughout the year. The reasons for choosing a professional development model that was based on regular meetings included the fact that it was face to face and not book or internet based.

The group has needed to accommodate new principals as they have moved into the group without changing the vision. This vision or purpose was continually evolving but there were clear understandings by each of the longer-term principals of what the cluster was for and the benefits that can ensure. Self-renewal was happening through the process of bringing in new members and adjusting to accommodate their skills and needs. It was also coming from the projects that the cluster had initiated, from professional readings and organized visits to other schools and speakers. All principals have participated in larger regional principal conferences. Occasionally there was a need to reach out further than this cluster but it was for gathering information for use within the cluster.

\section{How professional development supports leadership, collegial support, collaboration, and classroom practice.}

\section{Leadership}

P decided that this was going to be his year for taking a leadership role in the cluster so he offered to be the convener. The way that he has behaved and acted in the leadership role has played a big part in his motivation this year. $\mathrm{P}$ has a concern for the issues that face smaller school principals and he now feels able to speak out on some of these within other forums.

Comments from the survey from other principals included statements like; I have become more confident, gained reassurance, appreciated the opportunity to lead and become more reflective The chance to lead beyond his own school was a comment from another principal. One principal said that he had not seen many examples of principals as leaders 
and now had some role models. Another said that he had broadened the concept of how leadership can and cannot work.

\section{Collegial Support}

Comments from the survey included; there is always someone who can answer and advise, there is a safe place to share concerns and trust within the group has made me confident to share ideas and challenges. Another comment was about forming close relationships with other principals who are in similar situations. One principal felt that the group actively supported one another not just with the job of being a principal but also maintaining good health. Finally a principal said that he felt leading leaders is truly collegial " These folk are your peers. Understanding their needs and situations helps you gain a better understanding of your own".

C said that being involved with the cluster has made change a lot less frightening and given principals a sense of being in control because they have been able to confer and plan for change together. C says that in many cases it has sped up change for him, as he has been able to use a shared timeline with other principals to pace progress.

\section{Collaboration}

Comments from the survey indicated that collaboration has always been needed for sporting and cultural events and that isolated schools need people who can work with and for other people. A principal observed that some principals don't work collaboratively but in 2003 there were folk who understood collaboration and the benefits from it. Another principal said that the cluster was a great combination of thinkers and doers and that the principals worked together sharing skills and resources” the way it should be”. A principal said that he/she had learnt to be more open and collaborative in the school and with other schools as a result of being involved with the cluster.

\section{Classroom Practice}

Principals indicated that there were opportunities to view colleagues in action at events and in their classrooms but the future focus could move from their roles as principals to teaching and classroom practice. When principals attend courses they discuss outcomes 
with fellow principals sharing ideas for better teaching and learning and management systems.

$\mathrm{M}$ had been inspired by others to get back into reading about teaching and learning. During a recent teacher only day she decided with her staff to allocate a day for professional reading. Each participant found one key objective for the term, which they took back to trial in the classroom. $\mathrm{M}$ felt that the venture was successful because the task was manageable. In the future $\mathrm{M}$ would like teachers to have time together with two or three days a year of professional development similar to the principals. Teachers need time to focus on their interests. $\mathrm{M}$ felt that everyone was rushed and meetings were too hurried to allow time to explore new ideas. She thought this would help the transfer of professional development into classroom practice.

There were benefits for students from the principals' involvement with the cluster as can be seen in Table 4.5. Students and their parents are isolated too. C reminded us that parents do not realise it because they often have not had wider experiences. Students who attended small schools limited their world to that of the school and the world of their parents. When the principals interacted with other principals it removed some of the isolation factors from that school and the school community. C said that there was a trickle down effect to the whole community.

Sports and cultural events planned through the year were when teachers, parents and students met enabling them to see a whole new range of abilities and ways of doing things. C said that isolated schools continually needed to find ways to help students mix with others. These events were a major part of the school curriculum. There were often difficulties with the weather and travel arrangements. To attend any function students and their parents needed to leave early driving or boating for two hours before reaching the main road. This made it a very long day before doing any sport or other activity. Sometimes the school party would arrive late because of travel problems and this was always disappointing. Deciding whether to cancel or carry on when the weather was doubtful was another anxiety. C said he placed a lot of value on 'going out' both for himself and for the parents and students at the school. 


\section{Table 4.5: Benefits for schools from participation in the cluster}

School benefits

no responses

Increased social interaction for students

Wider experiences for students

Whole school (including parents) integrated into wider community

Competition at a higher level

More effectively run school

Students’ needs met through transition project

Improved leadership and management skills

Parent interactions through cluster events

Collective consultation with Maori

Shared development of policies and procedures

School has a principal with networks

PD opportunities across cluster schools enabling

sharing of staff skills, interests, experience, and knowledge.

There have been significant changes in schools through the involvement of principals in the cluster. One principal identified that there is more competition through participating in sports events. Another identified more standardized approaches to doing things after discussion such as expectations of behaviour and participation on sports days and specific training programmes for those events. After one principal was involved with discussions about leadership at the cluster meetings he made changes in his leadership and management style at his school. Another principal felt that his school might be 'out of the loop' in many areas such as curriculum, policy, property or assessment if he was not actively involved with the cluster.

One principal had strong comments about the need for professional development for principals. S felt that it was important that principals had specific professional development with opportunities for open and frank discussion where they were able to get good advice when it was needed. Often the issues are to do with the staff with which the principals are working. "There is no where to go when you are a brand new principal and needing to get to the nitty gritty straight away." 
P said that during the last six years the most useful professional development for him has been that which has been sourced to meet the needs of the cluster and it has been an interactive process. $\mathrm{P}$ is not enthusiastic about the provision of 'set pieces' of professional development and no longer feels prepared to take the risk that what is offered will meet the specific needs of his school community. P also describes the difficulties of traveling to main centers to access outside professional development courses. The time that the courses are offered often requires $\mathrm{P}$ to be away two days from his school and this generates two problems, finding a relieving teacher and funding.

C felt that some professional development that is offered is too broad and generalized to be useful for him and his school. He says that if you have control over what you take from it and what you do with it, professional development works. He suggested that, "Sometimes professional development from other providers is not so much about what you want but it's more about what other people want you to take back." By comparison when C drives for one and a half hours to a cluster meeting he says he looks forward to taking new ideas to be developed with his peers and to bring them back to trial He is always looking for efficiencies and ways to fine tune things.

Professional development needs to be based on what principals or teachers need and not something they already know. According to $\mathrm{S}$ the appraisal cycle should identify what principals or teachers need and should be accessing for their professional development. There was a lot of support for professional development from the college of education and other providers but "only schools as a whole can change the culture of a school."

Good professional development for new principals according to $M$ includes baseline information about reports, property management and how and where to access information which is specific to the location. New theories and research are interesting for her because there were never the same opportunities for study as a classroom teacher. She now shares new thinking from the cluster with the staff and they are expected to do the same when they access professional development otherwise M asks "why do we bother doing it?" 
Summary

Cluster professional development has given the principals involved a lot of control over where they meet, how often, planning of the agenda and priorites for professional development. The principals are choosing to focus on their strengths as well as their needs when making decisions about their professional development.

\section{Key Findings from the Results}

Why are the principals of six rural schools choosing to cluster for most of their professional development?

Principals in this cluster value professional development that is specifically for principals. Their need for social interaction is as strong as their need for information and new knowledge. Location and isolation from other professionals is partly overcome by technology that is being used enthusiastically but there is still a desire to regularly meet face to face with other educators who share the same school cultures.

How is professional development being achieved?

A climate of trust and respect has enabled the principals to use their cluster for support and to provide support with opportunities for leadership, collaboration, reflection and professional dialogue. These are needs that they can not satisfy within their own isolated schools.

The cluster meetings are not the only professional development choices for the principals in the study. Three of the six are participating in the literacy leadership contract, two are involved with visual art workshops and two are attending principal's induction programmes. Twelve professional development initiatives were listed in the survey by the principals. (Table 4.3) 
What are the factors sustaining the cluster model?

While acknowledging that their needs can be met through the cluster the principals have indicated that there are also benefits for their students and communities from cluster involvement. Sometimes the benefits are not easily recognized or linked to the cluster model because they are not curriculum based. It would be easier to describe this cluster model's activities as unequivocally professional development if they were curriculum based.

The transition project has illustrated how the group has become highly motivated to pursue a particular focus. This project has taken the cluster into research with opportunities for feedback to their communities, future action, policy development and change. This has helped cluster involvement to be recognised by the schools' communities and their boards of trustees as beneficial and an important part of each principal's role in their school and one, which they support so that it continues.

Funding of small projects by the ministry of education has helped the cluster consolidate its function as a cluster that meets for more than sports planning. The original mentoring contract has had a considerable influence on the collaborative management style of the cluster, which the results have shown was attractive to all principals in the cluster in 2003. The cluster is also being sustained by a high level of commitment from each of the principals. They attend most meetings and keep in communication between meetings; they have established close working relationships with their colleagues and show concern for each others’ professional and personal well being.

\section{Summary}

This chapter has reported the findings from a variety of data gathering methods. The researcher has selected from the vast amount of data collected what was considered important for the study. The findings from the results have been organised under the three research questions and will be discussed in the next chapter, chapter five. Discussion. 


\section{CHAPTER FIVE}

\section{Discussion}

This study has explored why the principals of six rural schools have organised themselves to meet regularly for professional development, how they have achieved a professional development, and identified some of the factors that sustain this choice. In this chapter the results from the data gathering will be discussed in relation to the three research questions. It will conclude with a description of the limitations and the implications of the findings.

\section{Why are the principals of six rural schools using a cluster model for most of their professional development?}

The findings from the study have challenged the conventional understanding of what constitutes professional development. They have shown that the principals of six rural schools have specific expectations from their professional development with a major need for regular interaction with other professionals who have a shared vision and culture. The study has explored how the cluster was organized and described the specific needs of principals and their rural schools

The study has shown that the principals in the cluster are not traditional, passive receivers of prescriptive programmes, as described by Lieberman (2000). One of their major needs was relevant professional development that supported their roles as principals in small communities where they were leaders and agents of change. The principals in this study meet together when and where they choose. Overtime the meetings have changed as they have catered for the needs of the group. In 2003 there were opportunities for professional input and leadership, which were valued by the group. An example of the group's capacity to manage a research task, plan for the implementation of change and the sharing of knowledge within their school communities is the transition project.

The transition project came from the perceived need of the principals for more information about what actually was happening within their school environments. When professional development rarely draws on teachers’ own experiences, it makes it difficult to accomplish 
the purpose of the professional development. Darling-Hammond et al., 1998. found that many initiatives take little account of the teaching context and do not view it as a rich source of problems for stimulating learning with an emphasis on collaborative planning, teaching and decision-making Because it was drawing on their own experiences and observations and the outcomes were extremely relevant for improving their students' learning outcomes, the transition project became an important part of the professional development agenda for the year for the cluster.

As has been shown by Spencer (1994) in his report on visits to six rural schools, different models of professional development produce different outcomes. Like perspectives five and six of Spencer's report, ( Problem Orientated Model and Facilitative Needs Based Model ) the principals in the cluster study believe that they have sufficient resources within their cluster to provide for their professional needs. One principal said, "We set the focus. We seek the resources. We meet the real needs at the time they are needed". The principals believe that they have a vast untapped pool of knowledge, skills, past and present experience within their cluster. As in the findings from Bowie's (1996) study of a remote rural school community in Victoria, Australia, the principals believed that they knew what they needed because of their close links with each other and with the needs and attitudes of their rural communities. Because of the similarities of their rural communities, the principals consider their professional development needs are similar and could be provided for by those within the cluster and, when they are not, they decide who, what, when and where they should go to gain the extra support they need.

According to Spencer (1994), the next stage of the knowledge acquisition process is when educators move out of the school environment to 'glean and garner outside' for ideas, strategies, techniques and visions and bring them back, expanded, enhanced to embellish and empower the group. (p.45). This has started to happen for the principals in the study when they have sought outside knowledge, resources and professional leadership. However, they have fiercely guarded the right to choose the source, location, time frame and delivery style in order to avoid the negativity of past experiences of outside professional development provision. Researchers, Lieberman and Grolnick (1996), found similar results from a study of sixteen networks in America. Networks allowed participants 
to direct their own learning while "sidestepping” the limitations of hierarchies, geographic locations, and institutional roles. (p.292)

Providers of professional development, especially those working with rural schools with unique requirements, need to consult and co-construct knowledge from principals based on findings from their daily work. Facilitators need to provide a learning environment that encourages learning to occur for everyone including himself or herself. Lieberman (1995) claims that other people's knowledge is not more important than that of the classroom teacher or school principal. Not only does the outside provider need to know the school environment and the community, they also need to have established personal relationships and credibility with the teachers or principals with whom they are interacting. Hargreaves (1992) suggests that teachers learn best from other teachers, from those who have experienced teaching and learning and just like all learners it needs to happen in a climate of support. This cluster is providing the conditions for this to happen.

Ownership of professional development can be linked to the level of participation and choice that exists in the professional development for the participants. According to Clark (1992), principals and teachers are capable of taking charge of their own professional development and should not be characterised as passive, needy, deficient and homogeneous. In addition, Clark says we need to recognise that adult development is voluntary and there is a greater chance of ownership if the individual participant does some self-exploration to become a " designer" of his/her own professional development. When the principals in the cluster were able to create, produce knowledge, and make decisions about their professional development, the practice encouraged new leadership roles such as mentors. Darling-Hammond, Cobb and Bullmaster (1998) found similar results in their studies. The principals have been encouraged to feel that they are members of a learning research-based profession that Barber (1996) says is an essential concept of professional development.

When the source of the knowledge as described by Hoban, (1997) is from outside to inside there is often a mismatch with the outcome described by the principal in the study, that he felt that he was receiving what other people wanted him to have rather than what he wanted. One principal commented that some professional development providers offered 
information that was too broad and generalized to be useful in his school. Another principal believed that providers of professional development think that their area of expertise is all that matters and they do not take into account the whole job. He wanted professional development that fitted with his identified appraisal goals. He said he rarely sought information or knowledge from other sources because," They are faceless and I don't know what they know. I don't know what I can actually ask without doing lots of scene setting.”

This cluster can be described as a group of principals, who have chosen to meet regularly, for professional development, which they design, develop and deliver. The reasons for meeting together on a regular basis are not solely sustained by the need for professional development. Lieberman (1995) suggests that being able to work together collaboratively enables participants to make in-depth social as well as professional connections. Teachers and principals learn best the way that students learn with active involvement, thinking, and articulating about what they learn with peers with whom they feel comfortable. The administration of a cluster needs to be responsive to the needs of the participants and one of these may be investment in establishing social as well as professional connections. But these principals developed their own professional development agenda because they considered themselves significantly unique, with different needs and cultures from urban or semi-rural schools for which the content and delivery style were usually directed.

The principals have made sense of educational requirements by adapting packages to fit their individual school communities. This is important because principals, according to Barbar (1996), need to reassert their professional judgment on educational policy so that they can take charge of their own learning. He says that this is the key to providing places where both students and teachers keep learning and become life long learners.

Principals, like teachers, are required to examine their own practice, to construct new roles and expectations about student outcomes, and to take control and responsibility for fashioning change that is relevant for them and their schools. In order for this to happen, principals and teachers need to engage in principal-to-principal, teacher-to-teacher, schoolto-school collectives to share and explore both problems and possibilities. Lieberman (1995) asks why teachers, who are also learners, are denied the wide array of learning opportunities that engage students in experiencing, creating and solving real problems, 
using their own experiences while working with others. For principals in isolated locations, this is not only a challenge, it is imperative in order for their personal and professional needs to be met. When they do this there is also a realisation that help, helps.

Rural schools, like the schools in the cluster, often need to include the community in a whole school approach to effect change. Spencer (1994) sees this as the first step to getting staff development right for rural schools. There can be enormous cultural distance between a rural community and the policy makers who influence the kind of curriculum that is offered. Principals in the study frequently reminded the researcher of their responsibilities to their isolated communities. They planned carefully so that the parents of their students could participate in events such as camps or visits 'out' to music, art, dance or drama performances. They knew that these were rare social and learning experiences for the parents as well as for the students. They also knew that with parent support there was a greater chance that the school would become the "steppingstone" for their children to the world outside. (p.51)

They showed that they were mindful of the impact of new knowledge and change on the communities and their children like Bowie (1996) who found a picture emerging of a community protecting itself from the outside world The community in Bowie's study saw itself as special, reproducing itself in its children and concerned about decisions made for them by people in far away cities.

When decisions are made for communities by people from other cities or based on reports from other countries there can be resistance and dissent. The model from Andalusia (Estebaranz et al, 2000) addressed this issue by moving control from the city to the regions. It no longer provided on-going professional development for teachers centred on the university and was a more independent model managed by teachers themselves. The Andalusia model does receive external funding based on the presentation of a 'work project'. The findings of this study are similar to those from the Andalusia model that developed a more democratic and more grass roots professional development model but still with a choice of external support. 
Some researchers confirm that change within a rural school has to be understood and supported by the community to succeed (Bowie, 1996 Spencer, 1994). The six schools are located in similar communities so the principals have commonalities that link them. They all serve farming communities such as sheep, dairy, deer, fishing and mussel farming and are located out of main centres. They all have students who come from isolated homes and travel to and from school by bus, boat or farm bike. They are all in schools that have been in existence for over one hundred years in communities that see the school as a significant community focus. They all have families who consider themselves well informed through using their school's library, reading, newspapers, watching television and using the Internet. They all serve communities where there is a culture of belonging for people born within the communities. Tourists and transient people, though, are considered outsiders, as are new arrivals, including new principals or teachers.

It has been found that the principals have been supported and encouraged by their communities in their involvement in the cluster professional development. This is unlike the study from Schmuck and Schmuck (1990) who found in small town schools in America, the academic side was left to the professionals and the community was not involved in discussions about teaching and learning. The concept of a learning community did not seem to be part of the culture. The small town school was not supported while support was evident for football, the band and other community entertainment. Schmuck and Schmuck (1990) recommended that assistance be provided to increase access for educators to programmes from outside agencies, encouraging change to go beyond what small town educators could initiate themselves. This is a different finding from the cluster study, where the board of trustees and the students and parents of the schools were kept informed and actively involved. The community recognised the benefits for them from the involvement of their principal in the cluster.

\section{How is professional development achieved?}

The principals indicated that they had a need for regular professional interaction in a supportive collaborative environment that was not judgmental. They liked to share, plan, collaborate and reflect with like -minded people that they knew and trusted (Fullan \& Hargreaves, 1992). In Andalusia, similar collaborative approaches enabled teachers to 
manage their own professional development, allowing them opportunities for reflection and the exchange of knowledge and skills. Like the principals in the cluster study, the Andalusia teachers set their own focus, chose their own resources and timeframe for their meetings (Estebaranz, et al 2000).

The ways that the cluster worked together was interesting. Schmuck and Runkel (1982) identified a framework for exploring the extent to which collaboration was occurring within a group and this was used and reported in the results. One of the features of the framework was the suggestion, that a group acts with purpose and gets things do This was achieved in the cluster through regular structured meetings that have helped the participants become a group with a focus. The meetings make an essential contribution to the professional lives of the participants because, through meeting together regularly, they view themselves as professionals an outcome also noticed by Clark (1992). They can focus on their real and daily concerns that Parsons (2000) considers is important for any professional development. They also see themselves as learners, not just teachers, as suggested by Dimmock (1995).

The researcher found that one of the most important features that emerged in the results from using the description of group process by Schmuck and Runkel (1982) was the evidence of a high level of interdependence There was an expectation that all would have input and that each contribution would be valued, regardless of the participant's age, school size, or experience. The lack of hierarchy was reflected by the spontaneous comments from the principals during the observation of the meeting although there were more verbal contributions noted from those who had been in the cluster longest.

From the findings it seemed that during the meetings, there was adequate time for social interaction and professional exchange. One participant described being involved in the cluster meetings "Sometimes it is like experimenting to see where the journey will take us." The meetings were structured sufficiently, with an agenda, to meet the various needs of the participants and this included giving time for thinking and reflecting a high priority. Day (2003) observed that reflection sometimes occurs informally with peers as well as formally in organised networks. There were indications that this was happening regularly within the cluster. 
It was apparent that the meetings were providing an opportunity for reflection for the cluster principals, which is essential for their complex role of leadership and responsibility within an isolated school community as found by Natchigal (1994). The meetings have made an important contribution to the social and professional lives of the principals in the study. They are making it possible for principals to reflect and gain knowledge that they are unable to achieve in their own schools.

Principals of rural schools have often had limited experience in the role, yet the findings suggest that rural schools and their communities need principals who understand the skills of leadership. Principals in the survey identified that they were becoming more confident because previously they had not seen examples of principals as leaders but now they had role models. These principals had strengthened their role as principals in two levels as described by Fullan (1985). First, they had a specific responsibility and second, general ongoing development through interacting with their peers, receiving ideas, trying them out, engaging in more discussion, and more action. They had also broadened the concept of how leadership can and cannot work. Some principals had an opportunity, for the first time, to lead beyond their own school. They had begun to appreciate the relationship between collaboration, reflection and leadership and were becoming more confident in all their practice which was an outcome also reported by Day (2003) and Hoban (1997). The principals in the cluster who were principals for the first time were able to gain an understanding of these important aspects of good leadership.

Some principals said that the trust within the group had made them more confident and able to share ideas and challenges not only in the cluster but in other forums and this was also found by several writers, Darling-Hammond andMcLaughlin, (1995); Hargreaves, (1992); Lieberman, (2000); Meier, (1992). The principals formed close, friendly relationships with principals who worked in similar situations so they actively supported each other in the job and in their health. One principal said that leading leaders is truly collegial because they are your peers. He felt that understanding their needs and situations helped him gain a better understanding of his own needs. 
All of the principals in the study felt that they had a safe place in which to share concerns or celebrations and appreciated that there was always a colleague to answer questions and advise. Collegiality is not easy to achieve yet the findings suggest that there was a high level of collegiality within the cluster. Hargreaves (1992) warns that contrived collegiality may destroy the very goal that is being sought. It may intrude upon the spontaneous, informal, open, personal discussion between teachers and their colleagues and under-mind the existing vital interpersonal foundations of a school culture. This was not the case in this study because the level of involvement in the cluster was voluntary. It was evident from the findings that discussions were frequently open, spontaneous, and informal with no signs of being contrived.

Isolated schools need people who can work with and for other people so collaborative approaches are essential. The principals who were in the cluster in 2003 liked to work this way but conceded that not all principals liked to work collaboratively. Collaborative cultures do not evolve quickly so they are not attractive to administrators wanting swift implementation expedients. The principals felt that the present cluster of principals understood collaboration and the benefits from working in this way, so it was embedded in every thing they did. One principal in the cluster said that the principals work together collaboratively, the way they should. As a result she had learnt to be more open and collaborative in her own school environment as well as when interacting with other schools.

All participants in the study felt that teaching practice could be a future focus for the cluster. They frequently viewed colleagues interacting with staff and students, both in and out of their classrooms but had not set up planned observations or visits. When they attended courses from outside providers, they discussed the outcomes with fellow principals and .as a group, shared effective systems for teaching and educational management. This was confirmed during the provider interview when it was suggested that this cluster of principals had gone past the” nuts and bolts stage” and were into reflecting on better teaching and learning. 


\section{What factors sustain the cluster model?}

There are many factors sustaining the model, some are to do with the sense of ownership and control that the principals feel they enjoy over the creation and development of a homegrown initiative. There are also significant benefits for the principals, their students and communities from involvement in the cluster. Perhaps, more importantly, the principals indicated that it was the collaborative model with shared responsibilities that attracted them and kept them involved. It is not surprising to find that Lieberman and Grolnick (1996) found that unless involvement in the network was compelling then engagement dwindled.

Principals who work in isolated schools are very motivated to meet and interact with other principals not only because they are professionally lonely but also because they believe they will get the knowledge they require and in this cluster, it will happen in a safe environment. Some writers suggest that these factors are not peculiar to the principals of rural schools. Writers such as, Friend and Cook (2003) Fullan and Hargreaves (1996) Fullan (1999) Lieberman (2000) Little (1993) and Sparks (1996) describe a supportive environment for all professional development, as one where, reciprocity can occur, that includes collaborative approaches, that is voluntary and is concerned with relevant knowledge. Being able to reciprocate, has encouraged principals to feel that they are members of a learning research-based profession which Barber (1996) says is an essential concept of professional development.

The findings suggest that communication with each other is an important contributor to the sustained success of the cluster and this includes occasionally taking opportunities for sharing new skills and knowledge from outside the cluster. Technology is a positive development that is acknowledged as making a significant difference to increasing communication between the principals, between meetings, but it does not satisfy their need for ongoing social and professional contact.

There were two significant findings in the results that were also relevant in the American study of networks, described by Lieberman and Grolnick (1996). The first was funding and the second, adding new members. The mentoring contract and other initiatives offered by the Ministry of Education have provided limited funding for various projects. This has 
allowed the cluster participants to plan and lead initiatives that they consider relevant and worthwhile, while adding status and purpose to the cluster meetings. However, unlike the American example, some funding opportunities have been rejected by the cluster because they were considered too restrictive or Ministry of Education outcome focused. The principals in the study believed that they would be required to comply with the fund provider's own agenda and constrained by the assessment criteria of the results. It was surprising to find that the participants in the cluster survey did not consider funding an important issue, yet fifteen of the sixteen networks in the American study received significant amounts of funding and the level of funding was considered essential for the success of networks.

Like the American study, there came a time when the cluster felt that they should add more schools to the cluster. The invited schools dropped away quite rapidly because, within a short time, they found that they did not have the same needs because they came from different locations with different needs and were better to develop their own cluster that included geographically closer schools. In the American study the need for like-minded participants to add to an existing network became an issue within the membership. In the cluster study, the six principals wanted to increase the membership without realising the impact that geographic location was having on them and their schools.

\section{Limitations}

There were five main limitations to this study.

The first was with difficulties in gathering data within the year 2003. The difficulties were with the geographic location of the schools, the weather and the heavy workloads of the principals. Several meetings were rescheduled because of unexpected happenings within the schools. One significant observation was rescheduled from the end of 2003 to the beginning of 2004. By this time, three of the six principals involved in the study had changed and there was a change in the researcher's employment. Travel to the schools by the researcher required air and considerable car travel. Some funding and release time were available for 2003 but when the study spilled over into 2004, there was no funding available and limited release time. As the group had also significantly changed, the study 
had to end with some small modifications to the original plan. The second provider interview became an informal discussion instead of a semi-structured interview. A further attempt to search through the historical files had to be abandoned.

The second limitation was with one of the six principals originally deciding not to participate in the study. As the study moved along, this changed and the principal participated in all but the semi-structured interview. While the researcher understood the reasons for this, (new principal and too busy), it would have been extremely valuable to have the perspective of a new principal for the whole study.

The third limitation was with the researcher's prior involvement with some of the principals through participating in Ministry of Education contracts. The researcher attempted to address any bias that could occur by making sure that data were gathered and interpreted without bias. Transcribed interviews were checked with the participants and corrected when necessary Colleagues who were not involved in the research were asked to comment on the conclusions from the findings and compare with the researcher's results. Knowing the principals and their professional development provision was useful for approaching the study.

The fourth limitation to the study was because only one cluster was investigated. The researcher is cautious in generalising the findings to all clusters.

The fifth limitation was that the study has investigated the research question only through the principals’ perspective. It has not sought comment from parents, teachers, teacher aides, students or support staff or attempted to measure the impact of the professional development on the learning outcomes of the students.

\section{Conclusions and Implications of the Study}

A perception of what professional development is and what form it should take varies from person to person, school to school and country to country. When asked if the model could be effective in an urban setting, one principal in the study said it could work if the focus 
was on a specific curriculum area such as literacy or ICT. The researcher took this to mean that rural principals perceive that urban principals have different needs from them for their professional development. The difference was that the focus of the cluster meetings in the study, was not solely curriculum based. It would have been easier to describe the model as professional development if it had been. The focus was flexible and responded to the personal and professional needs of the principals. It was not considered to be a 'quick fix' approach but rather an enduring tool for strengthening school improvement in the cluster.

Regardless of the focus, principals in this study have indicated that choosing the source of knowledge, developing supportive relationships, sharing responsibilities and leadership, and providing opportunities for social interaction were important factors when they were considering professional development. These were the reasons why the principals in the study were choosing this option for their professional development. To question if this model was indeed professional development would suggest that these identified factors are not characteristic of effective professional development.

The principals in the study have achieved professional development in a variety of ways. The case study has shown that in 2003 they had developed a high level of collegiality, collaboration and self-determination. These three attributes have enabled professional development to occur in a learning environment that many researchers describe as best practice. The isolation from other professionals with whom they can interact has forced them to seek out like-minded people and voluntarily form a cluster. This cluster of principals has chosen over time to create a model of professional development based on what they consider are their unique needs. One of these needs is to meet regularly and interact with others socially and professionally. The freedom to make choices, based on these identified needs, remains a strong part of the cluster's philosophy.

Getting professional development right for the principals of rural schools includes recognising that each principal supports a learning community that indirectly benefits from their new skills and knowledge. The cluster professional development model represents a much larger group of people than the six principals. It is this collective responsibility and not just the isolation that sets these schools and their principals apart. Professional development for these principals will trickle down into their communities, so they have 
both personal and community needs to recognise and manage. Principals in the study have support for their involvement in the cluster from their board of trustees and through them, their communities. Their support and encouragement occurred because all stakeholders including the principals valued the outcomes from the cluster professional development. The board of trustees and the school communities play an important part in the professional life of the principals in these communities.

One of the most positive factors that contributed to sustaining positive outcomes for the cluster has been the mentoring contract. This contract that provided initial funding for a cluster project had a significant influence on the direction and management style of the early development of the cluster. It strengthened the philosophy and purpose of the meetings and as one principal said, "It gave us an excuse to do the very thing we needed and wanted to do." It allowed the group to meet with a shared focus for learning and to engage in professional dialogue. Mentoring has since become embedded in the way the cluster is structured and operates. This was the strongest identified factor that sustained the cluster model.

\section{Recommendations}

This study concludes with four recommendations for future research.

Firstly, research is needed to confirm that principals, who combine the role of being principal and teacher, require different professional development from non-teaching principals.

Secondly, research is needed to find if teachers and principals of rural schools have different professional development needs from their urban colleagues. Principals in this study have given some insights into the complexity of working in isolated rural communities.

Thirdly, while this study has shown that clustered professional development can effectively offset the negative effects of isolation and provide opportunities for leadership, personal and professional growth, research is needed to investigate the impact that clusters have on 
professional development outcomes in other settings. None of the schools in the study were in competition for students to add roll numbers. In some settings, this may be a significant barrier to effective clustered professional development.

Finally, research is needed to investigate whether the provision of professional development by outside providers is more effective when it uses the strengths of the participants. Ownership and generalisation of new knowledge will continue to be an issue while teachers and principals are led to believe that other people's understandings of teaching and learning are more important than their own.

\section{Summary}

This chapter has reported on the findings from the study of six rural schools and their professional development model. It has used a framework for reporting, based on a similar study done by Estebaranz et al., (1999) in Andalusia. The framework has helped the researcher to look at the cluster model from several directions and answer the research questions: why the principals of six rural schools are using a cluster model for most of their professional development; how professional development is achieved and what factors are sustaining the cluster model.

The study has shown that, the principals at the time of the study were using the cluster model, because it catered for their personal and professional needs. Professional development was being achieved with an emphasis on, reflection, collaboration and interpersonal relationships. Leadership opportunities and the sharing of new knowledge were valued aspects of the agenda. The cluster model was sustained by being, voluntary, flexible and responsive to the mix of participants. During 2003, the principals were attracted to the cluster by the mentoring approach that was strongly embedded in the model. 


\section{References}

Baird, J., \& Mitchell, I.J. (Eds.). (1987). Improving the quality of teaching and learning: An Australian case study-the PEEL Project. Melbourne: Monash University Printing Services.

Barber, M.(1996). The learning game: Arguments for an educational revolution. London: Gollancz.

Berman, P., \& McLaughlin, M. (1978). Federal programmes supporting educational change: Vol.8. Implementing and sustaining innovation. Santa Monica, CA: Rand.

Birman, B.F., Desimone, L., Porter, A.C., \& Garet, M.S. (2000). Designing professional development that works. Educational Leadership, (pp.28-33).

Blackmore, J. (1999, November). Framing the issues for educational redesign, learning networks and professional activism. Deacon Centre for Education and Change. Australian Council for Educational Administration. Monograph Series. (25). 8-43.

Bogdan, R., \& Biklen, S. (1992). Qualitative research for education: an introduction to theory and methods. Boston: Allyn \& Bacon.

Bolam, R. (1988). “What is effective INSET?” In Professional Development and INSET: Proceedings of the 1987 NFER Members Conference edited by the National Foundation for Educational Research. Slough:NFER.

Bolam, R. (1990). Changing roles of the shareholders in England, Wales and Australia. In Joyce, B. (Ed.), Changing school culture through staff development. Virginia: 1990 Yearbook of the Association for Supervision and Curriculum Development. 
Bowie, B. (1996). Flexibility and technology versus the tyranny of distance: Pursuing quality outcomes in a remote rural school. In: C. Boylan \& P. d'Plesse, (Eds.), Rural education: quality experience quality outcomes (pp.59-73).Toowoomba Queensland: Society for the provision of Education in Rural Australia(SPERA) ( Proceedings of the $12^{\text {th }}$ National Conference 1996 Hobart)

Burt, E. \& Davison, L. (1999). Teacher professional development - then and now and in the future. New Zealand Journal of Educational Administration. (pp.44-52). Palmerston North: NZEAS \& AUPC.

Buchanan, S. (1993). Development and implementation of professional development programmes in six rural primary schools. Research Affliliate Scheme, Department of Education Studies The University of Waikato Te Whare Wananga o Waikato Hamilton, New Zealand.

Clark, C. M. (1992). Teachers as designers in self-directed professional development. In A.Hargreaves, \&M.G. Fullan, (1992) Understanding Teacher Development (pp. 75-84.)London: Cassell (with)Teachers College Press.

Clark, P. (2000). Learning schools, learning systems. London : Continuum.

Cochran-Smith, M. \& Lytle, S. (1993).Inside/outside:Teacher research and knowledge.New York: Teachers College Press.

Cocklin, B. (1997). The rural school as a learning community: Sifting the rhetoric to locate the reality. Paper presented at the Australian Association for Research in Education Conference., Brisbane, Australia.

Darling-Hammond, L., Cobb, V., \& Bullmaster, M. (1998). Professional development schools as contexts for teacher learning and leadership. In K. Leithwood, \& K. Seashore Louis, (Eds.), Organizational Learning in Schools. (pp.149-175).New York: Swets \& Zeitlinger. 
Darling-Hammond, L., \& McLaughlin, M.W. (1995). Policies that support professional development in an era of reform. In Practices and policies to support teacher development in an era of reform (pp. 2139). New York: NCREST 1995

Darling-Hammond, L. (1999). Teaching as the learning profession. Handbook of policy and practice. San Francisco: Jossey-Bass Publishers.

Day, C. (2000). Change and professional development. The costs of commitment. In C. Day, A.Fernandez, T.E. Hauge, \& J. Moller (Eds.), The life and work of teachers: International perspectives in changing times. (pp, 109-129) London: RoutledgeFalmer.

Day, C. \& Bakioglu, A. (1996). Development and disenchantment in the professional lives of headteachers. In I.F. Goodson \& A. Hargreaves, (Eds.), Teachers' professional lives. London: Falmer Press.

Day, C. (2003). The changing learning needs of heads: building and sustaining effectiveness. In A. Harris, C. Day., D. Hopkins., M. Hadfield., A. Hargreaves \& C.Chapman, (Eds.), Effective leadership in school improvement (pp.26-52). London: Routledge Falmer.

Dimmock, C. (1995). Restructuring for school effectiveness: Leading, organising and teaching for effective learning. Educational Management and Administration.23, (1), 5-18.

Estebaranz, A., Mingorance, P., \& Marcelo, C. (1999). Teachers' work groups as professional development: What do the teachers learn? In B.Moon., J.Butcher., \& E. Bird, Leading professional development in education. (pp.124-140) London: Routledge Falmer

Free, N. \&Nolan, B., (1988). A model for cooperative professional development in small schools. Journal of Teaching Practice, 8 (2), 28-35. 
Friend, M., \& Cook, L. (2003). Interactions: Collaboration skills for school professionals. Boston: Allyn \& Bacon.

Frost, D., Durrant, J., Head, M., \& Holden, G. (2000).Teacher-led school improvement. London, New York: Routledge Falmer.

Fullan, M. (1985). Change processes and strategies at the local level. The Elementary School Journal, 85 (3), 391-421.

Fullan, M., \& Hargreaves, A. (1992). What's worth fighting for in your school? Working together for improvement. Buckingham: Open University Press.

Fullan, M. (1993). Change forces: Probing the depths of educational reform. Bristol, PA: The Falmer Press.

Fullan, M., \& Hargreaves, A. (1996). What's worth fighting for in your school? New York: Teachers' College Press.

Fullan, M. (1999). Change forces: The sequel. London: Falmer Press

Good, T.L., \& Brophy, J.E. (1984). Looking in classrooms. New York: Harper \& Row.

Grossman, P.L. (1994).In pursuit of a dual agenda: Creating a middle level professional development school. In L. Darling-Hammond (Ed.), Professional development schools : Schools for developing a profession (pp.50-73).New York:Teachers College Press.

Hargreaves, A., \& Fullan, M.G. (1992). Understanding teacher development, London: Cassell (with )Teachers College Press.

Hargreaves, D. (1983). The occupational culture of teachers. In P. Woods. Teaching strategies. London: Croom Helm. 
Hatton, E. (1988).Teachers' work as bricolage: Implications for teacher education. British Journal of Sociology of Education, 9 (3), 337-357.

Hill, J., Hawk, K., \& Taylor, K. (2001). Professional development: What makes it work? Paper presented at NZARE Conference, Christchurch, New Zealand.

Hoban, G. (1997).Opportunities for knowledge building in professional development models. In Exploring professional development in education. Faculty of Education: Charles Stuart University. Social Science Press: Australia.

Hopkins, D., Ainscow, M., \& West, M. (1994). School improvement in an era of change. London: Cassell.

Hopkins, D. (2001). School improvement for real. London: Routledge Falmer.

Huberman, M., \& Crandall, D. (1983). People, policies and practices: Examining the chain of school improvement. Implications for action, a study of dissemination efforts supporting school improvement. Andover. M.A.: The Network.

Joyce, B., \& Showers, J. (1996). The evolution of peer coaching. Educational Leadership. (pp.12-16).

Lange, D. (1988). Tomorrow's Schools. Wellington: New Zealand Government Printer.

Lieberman, A. (1995). Practices that support teacher development: Transforming conceptions of professional learning. Phi Delta Kappan, 76 (8) 591-596.

Lieberman, A. (2000). Networks as learning communities. Journal of Teacher Education. 51 (3), 221-227. 
Lieberman, A., \& Grolnick, M. (1996). Networks and reform in American education.In L.Darling-Hammond, G.Sykes,(Eds.). Teaching as the Learning Profession "Handbook of policy and practice (pp.292312). San Francisco: Jossey-Bass Publishers.

Little, J. (1993). Teachers' professional development in a climate of educational reform. Educational Evaluation and Policy Analysis, 15 (20). 129-151.

Lyttle, S.L., \& Cochran-Smith, M.(1994). Inquiry, knowledge and practice. In S. Hollingsworth \& H. Sockett (Eds.), Teacher research and educational reform (pp. 22-51). Ninety-third Yearbook of the National Society for the Study of Education.Chicago: University of Illinois Press.

May, T. (1997). Social Research: Issues methods and process ( $2^{\text {nd }}$ ed.), Buckingham: Open University Press.

McLaughlin, M. (1990). The rand change agent study: Macro perspectives and micro realities, Educational Researcher, 19 (9), 11-15.

Meier, D. (1992). Re-inventing teaching. Teachers' College Record, 93 (4), 594-609.

Moffett, C. (2000). Sustaining change: The answers are blowing in the wind. Association for Supervision and Curriculum Development. Educational Leadership. (pp.35-38)

Nachtigal, P. (1994). Rural schools, rural communities-an alternative view of the future. In D. McSwan \&M. McShane (Eds.), International Conference on Issues Affecting Rural Communities, (pp.145-150). Townsville, Queensland : Rural Education Research and Development Centre, James Cook University. 
Newman, I., \& Wehlage, G., (1995). Successful school restructuring. Madison Centre on Organization and Restructuring of Schools. University of Wisconsin-Madison.

N.S.W. Teachers’Federation Small Schools Policy (1986 Annual Conference Decision). In N. Free, \& B.Nolan, A model for cooperative professional development in small schools. Journal of Teaching Practice, 8 (2), 28-35.

Nixon, J. (1992) The Accreditation of Curriculum Development: Enhancing the Process of Reflection through Accreditation: A new Partnership Between Schools and Higher Education, unpublished MA dissertation, Canterbury Christ Church University College.

O’Sullivan, P. (2000). What you don't know won't hurt me: Impression management, functions of communication in relationships. Human Communication Research, 26. 403-431.

Parker, A. (1977). Networks for innovation and problem solving and their use for improving education: A comparative over-view. Unpublished manuscript, School Capacity for Problem Solving Group. National Institute of Education. Washington D.C.

Parsons, R. (2000) The relationship between professional development and school improvement. Presentation Special Education 2000 Contract Coordinators, Wellington: Ministry of Education.

Poskitt, J. (2000 ). Towards successful school-based professional development. Paper presented at NZARE Conference, New Zealand.

Reeves, J., Mahoney, P., \& Moos, L.(1997).Headship: Issues of career. Teacher Development, 1 (1), 43-56.

Schmuck, R. \& Runkel, P. (1982) Group processes. (pp. 743-755 Encyclopoedia of Educational Research). 
Schmuck, P. \& Schmuck, R. (1990). Democratic participation in small town schools. Educational Researcher, 19 ( 8) 14-19.

Sergiovanni, T. (1992). Moral leadership: Getting to the heart of school improvement. (p.51). San Francisco: Jossey-Bass.

Showers, B. (1988). Student achievement through staff development: Fundamentals of school renewal. New York: Longman.

Smylie, M. \& Tuermer, U. (1995) Restructuring schools in Hammond, Indiana. In A. Lieberman, The work of restructuring schools . Building from the ground up. (pp.87-110).New York: Teachers College Columbia University

Sparks, D. (1996). Viewing reform from a systems perspective. The Developer, 2, 6.

Sparks, D., \& Hirsh, S. (1997). A new vision for staff development. Alexandria, V.A: Association for Supervision and Curriculum Development.

Sparks, D., \& Loucks-Horsley, S. (1990). Models of staff development. In W.Houston, (Ed.), Handbook of Research on teacher education (pp.234-250). New York:Macmillan.

Spencer, J. (1994). Staff development in rural schools-let's get it right! In D.Riley, (Ed), The rural community and its school: In partnership for the future. Society for the provision of education in rural Australia (SPERA) Proceedings for the $10^{\text {th }}$ National Conference held in Freemantle, Australia, 12-15 October 1994.

Stephens, E. (1984). Toward the construction of a research and development agenda for rural education. Paper presented at the National Conference on Building Partnerships for Quality Education in Rural America. Washington: Research in Education. 
Stoll, L., \& Fink, D. (1996). Changing our Schools: Linking school effectiveness and school improvement. Buckingham, Philadelphia: Open University Press.

Van Velzen, W., Miles, M., Ekholm, M., Hameyer, U., \& Robin, D., (1985). Making school improvement work-A conceptual guide to practice. Leuven, Belgium: ACCO.

Waller, W. (1932). The sociology of teaching. New York: Russell \&Russell.

WEB Research. (1997). Future scenarios for teaching, teachers and teacher education. Wellington: Centre for Research in Work, Education and Business.

Yinger, R.J., \& Hendricks, M.S. (1990). An overview of reform in Holmes Group institutions. Journal of Teacher Education, 41 (2), 21-26. 